Contract No. and Disclaimer:

This manuscript has been authored by Savannah River Nuclear Solutions, LLC under Contract No. DE-AC09-08SR22470 with the U.S. Department of Energy. The United States Government retains and the publisher, by accepting this article for publication, acknowledges that the United States Government retains a non-exclusive, paid-up, irrevocable, worldwide license to publish or reproduce the published form of this work, or allow others to do so, for United States Government purposes. 


\title{
CHRONIC IRRADIATION OF SCOTS PINE TREES (PINUS SYLVESTRIS) IN THE CHERNOBYL EXCLUSION ZONE: DOSIMETRY AND RADIOBIOLOGICAL EFFECTS
}

\author{
Vasyl I. Yoschenko, ${ }^{*}$ Valery A. Kashparov, ${ }^{*}$ Maxim D. Melnychuk, ${ }^{\dagger}$ Svjatoslav E. \\ Levchuk, ${ }^{*}$ Yulia O. Bondar, ${ }^{\dagger}$ Mykola Lazarev, ${ }^{*}$ Maria I. Yoschenko, \\ Eduardo B. Farfán and G. Timothy Jannik ${ }^{\ddagger}$ \\ *Ukrainian Institute of Agricultural Radiology of National University of Life and Environmental \\ Sciences of Ukraine (UIAR NUBiP of Ukraine) \\ ${ }^{\dagger}$ National University of Life and Environmental Sciences of Ukraine (NUBiP of Ukraine) \\ tSavannah River National Laboratory, Aiken, SC 29808, USA
}

\section{For reprints and correspondence contact:}

\author{
Eduardo B. Farfán, Ph.D. \\ Environmental Dosimetry Group \\ Environmental Science and Biotechnology \\ Savannah River National Laboratory \\ Savannah River Nuclear Solutions, LLC \\ Bldg. 773-42A, Room 236 \\ Aiken, SC 29808 \\ E-mail: Eduardo.Farfan@srnl.doe.gov \\ Phone: (803) 725-2257 \\ Fax: (803) 725-7673

\section{Part of the Savannah River National Laboratory HPJ Special Issue}

October 2011 


\begin{abstract}
To identify effects of chronic internal and external radiation exposure for components of terrestrial ecosystems, a comprehensive study of Scots pine trees in the Chernobyl Exclusion Zone was performed. The experimental plan included over 1,100 young trees (up to 20 years old) selected from areas with varying levels of radioactive contamination. These pine trees were planted after the 1986 Chernobyl Nuclear Power Plant accident mainly to prevent radionuclide resuspension and soil erosion. For each tree, the major morphological parameters and radioactive contamination values were identified. Cytological analyses were performed for selected trees representing all dose rate ranges. A specially developed dosimetric model capable of taking into account radiation from the incorporated radionuclides in the trees was developed for the apical meristem. The calculated dose rates for the trees in the study varied within three orders of magnitude, from close to background values in the control area (about $5 \mathrm{mGy}^{-1}$ ) to approximately 7 Gy $\mathrm{y}^{-1}$ in the Red Forest area located in the immediate vicinity of the Chernobyl Nuclear Power Plant site. Dose rate/effect relationships for morphological changes and cytogenetic defects were identified and correlations for radiation effects occurring on the morphological and cellular level were established.
\end{abstract}

Keywords: Chernobyl, plant uptake, dosimetry, radiation effects. 


\section{INTRODUCTION}

Until recently, scientists who studied biota contamination issues have had a tendency to believe that if a human being is protected, the environment is also protected. The Chernobyl Nuclear Power Plant (ChNPP) accident became one of the reasons for revising this concept. The ChNPP accident made over 250 thousand hectares of land unsuitable for economic activities and permanent human habitation. Under these circumstances, human beings have been protected due to evacuation and relocation (with the exception of the immediate period of the ChNPP accident); while the biota in the contaminated area has been continuously exposed to irradiation from the external sources (e;g; soil and vegetation) and incorporated radionuclides.

The area in close proximity to the ChNPP accident still contains high radioactive contamination levels (Kashparov et al. 2001, 2003), and assessment of the biota exposure in that area is essential. As early as the first few years following the ChNPP accident, radiobiological effects, both somatic and genetic, in plants inhabiting the contaminated areas were detected. Diverse morphological and genetic defects that have been present in plants inhabiting the contaminated areas to-date include changes in size, shape, and color of individual organs and their location in the plants (Shevchenko and Grynikh 1995; Frolova et al. 1996; Geraskin et al. 2003a; Pozolotina 2003, Oudalova et al. 2005). Specifically, numerous morphological defects have been detected in Scots pine (Pinus sylvestris) (Kal'chenko et al. 1993a, 1993b; Rubanovich and Kal'chenko 1994; Grodzinsky et al. 1995; Geraskin et al. 2003b). Scots pine trees, on one hand, are very sensitive to radiation and, on the other hand, they are the major forest-forming species in the Chernobyl Exclusion Zone (ChEZ). Therefore, systematic studies of this species would be especially important from both scientific and practical points of view. In this respect, Kozubov and Taskaev's (2002) study was specifically devoted to effects of radiation on coniferous forests of the ChEZ. They 
tracked the chronology of the arboreal contamination and assessed early post-Chernobyl effects, including those forests that no longer exist. Numerous observations of the radiobiological effects even on the morphological level were performed in the ChEZ, but very few studies were conducted that would have made it possible to clearly identify how radiobiological effects depended on dose rates. A lack of these studies was likely to be associated with the biota diversity and unavailability of dosimetric models for most species.

In this situation, a natural step forward was to select species that could serve as "markers" of irradiation for the entire ecosystem. Various approaches used various concepts, such as "reference organism", "reference animal and plant", "representative species", "feature species", etc., reflecting different criteria for selection of such species [the Environmental Modeling for Radiation Safety (EMRAS) Biota Working Group]. The creation of the EMRAS Biota Working Group in 2004 and the $5^{\text {th }}$ Committee of the International Commission on Radiological Protection (ICRP) in 2005 demonstrated a departure from the anthropocentric principle for protection of the environment, or at least an attempt to revise it. There has been an ample debate on what doses should be considered screening doses for the so called non-human biota (ICRP 2003; Fesenko et al. 2005) and approaches for developing dosimetric models for the biota (USDOE 2002; Beaugelin-Seiller et al. 2005; Beresford et al. 2005). It is important to note that the ChEZ is considered to be one of the major sites for acquiring required empirical data arrays and validating modeling approaches, and the $5^{\text {th }}$ ICRP Committee suggested that Scots pine (Pinus sylvestris) should be utilized as one of the reference plants for assessment of radioactive exposure on the biota.

This article describes studies conducted by the Ukrainian Institute of Agricultural Radiology (UIAR) in the ChEZ since 2005 to identify effects of chronic radiation and a frequency of occurrence of morphological changes as a function of a dose rate for Scots pine. One of the major components of these studies was to develop a dosimetric model for the apical meristem (tip of the 
bud that causes a shoot to grow) of this species. Currently, the dosimetric model has been developed and the dose rate/frequency of morphological changes dependence has been finalized. However, the described dose rate dependence for cytogenetic defects is likely to be updated and revised during future studies, specifically, when parameters of the defects are evaluated as a function of time.

\section{MATERIALS AND METHODS}

\section{Formation of the sampling plan}

The sampling plan for the project included several sites of the ChEZ with various contamination levels and one control site outside the ChEZ. The following criteria were considered for determination of which trees to include in the sampling plan:

Criterion A: The age of the trees should be approximately the same and make it possible to study the effects of chronic irradiation. In many areas of the ChEZ, precise parameters of the radiological situation in the acute period of the ChNPP accident were (and are likely to remain) unknown. Therefore, since it is important to accurately identify dose rates for the trees included the study, only those trees that originated no earlier than one or two years after the ChNPP accident should be considered;

Criterion B: Individual indicators of radioactive contamination of trees included the study should vary from the background values to the highest possible values that could be found in the ChEZ, with the contamination and dose rate values within this range being presented as evenly as possible; and

Criterion C: To minimize non-radiation effects, the trees included in the study should be located as far away as possible from major industrial sites, roads and other sources of environmental 
contamination. In addition, all the trees should to be located under identical or similar soil, terrain, and weather conditions.

To meet these criteria, the sampling plan included planted Scots pine trees that were 15-16 years old when the study started. These pine trees were planted soon after the ChNPP accident mainly to prevent radionuclide resuspension and soil erosion. The trees were located at three sites with various contamination levels within the $\mathrm{ChEZ}$ and one site (control site) outside the ChEZ.

The major site, the Red Forest site, is an Interim Radioactive Waste Storage facility (IRWS) located about $1.5 \mathrm{~km}$ west of the ChNPP. The Red Forest site is approximately a $2 \mathrm{~km} \times 2 \mathrm{~km}$ area containing subsurface trenches with buried contaminated trees that died during the ChNPP accident (the name Red Forest originated from the color of these trees resulting from the effect of the transient radioactive cloud) and the upper highly contaminated soil layer. The currently growing Scots pine trees were planted in that area in 1988-1989. The advantage of the Red Forest experimental site is that highly contaminated areas (trenches) alternate with areas with a relatively low contamination. Therefore, dose rates to the trees vary in a wide range, which is necessary for formulation of the dose rate/effect dependencies (according to Criterion B). The radioactivity distribution at the Red Forest site was studied in detail by the UIAR, the Institute of Radioprotection and Nuclear Safety (IRSN, France) and the Institute of Geological Sciences (IGS, Ukraine) within the frameworks of several joint projects (Bugai et al. 2005). The average ${ }^{137} \mathrm{Cs}$ and ${ }^{90} \mathrm{Sr}$ concentrations measured in the material in trench \# 22 (around which the sampled trees were selected) were $280 \pm 110 \mathrm{kBq} \mathrm{kg}^{-1}$ and $135 \pm 53 \mathrm{kBq} \mathrm{kg}^{-1}$, respectively.

However, the detailed characterization of the radioactivity distribution in the soil at the selected experimental sites was not a task of this study because the dose rate assessment for the trees was performed on different basis. Thus, to meet the requirement of Criterion B, it was reasonable to estimate the levels of the soil contamination at the sites rather than to obtain the 
detailed characterization. The radioactive contamination of soil at the Yaniv and Kopachi sites is by one or two orders of magnitude lower than at the Red Forest site. The contamination at the whole Yaniv area is unevenly distributed since it is an extension of the IRWS facility to the west. However, the contamination within the selected sampling site is rather uniform because of the absence of contaminated trenches. The contamination at the Kopachi site located approximately 5 $\mathrm{km}$ south of the ChNPP is more evenly distributed, with a contamination density of $2,000 \mathrm{kBq} \mathrm{m}^{-2}$ for ${ }^{137} \mathrm{Cs}$ and $750 \mathrm{kBq} \mathrm{m}{ }^{-2}$ for ${ }^{90} \mathrm{Sr}$.

Finally, the reference site is located approximately $40 \mathrm{~km}$ south of the ChNPP near the town of Ivankiv. The contamination at the reference site is evenly distributed and it is significantly lower than within the ChEZ. The average contamination densities at the reference site are $16 \mathrm{kBq} \mathrm{m}^{-2}$ for ${ }^{137} \mathrm{Cs}$ and $5 \mathrm{kBq} \mathrm{m}{ }^{-2}$ for ${ }^{90} \mathrm{Sr}$.

All trees at all experimental sites, including the Red Forest site, were planted. They are of the same age and have a similar population density. Although all the experimental sites have the same soil type (Podzoluvisol), the soil conditions for specific trees vary slightly vary, with.the most fertile environment found in the trenches of the Red Forest, while the Ivankiv reference site has a very low humus content. However, in general all other environmental conditions (except the radiation dose rates) at the different sampling sites are very close, which enables identification of the radiation effects.

The sampling plan included 619 trees at the Red Forest site, 260 trees at the Kopachi site, 150 trees at the Yaniv site, and 100 trees at the Ivankiv site. To minimize subjectivity, trees randomly selected from several rows at each site were utilized for the studies. The selected trees were labeled and a significant part of the selected trees were photographed. 


\section{Identification of morphological parameters}

For each tree in the study, its major morphological indicators were identified, such as age based on the number of tiers in the lateral branches, tree height using a light duty marked pole, and trunk thickness on the soil surface based on the trunk circumference measured by a measuring tape. One of the major dendrometric parameters - the diameter at breast height, could not be applied because most trees had branched out significantly lower than the breast height.

In addition, the presence of morphological change (morphosis) was visually determined and its type and age of its first occurrence for each tree was recorded. In spite of the diversity of the morphoses during the first few post-Chernobyl years, the current morphoses for the planted Scots pine species in all studied areas (including the reference site) are almost exclusively represented by the disappearance of the apical dominance, However, the frequency of morphoses is different at the various sites increasing with an increase in the amount of radioactive contamination. Such changes as increase or decrease of pine needle size, loss of needles by offshoot branches, and chlorophyll mutations are extremely rare. Therefore, with the limited sampling size of the study, it is practically impossible to identify statistically valid frequencies of these changes as a function of dose rate. Disappearance of the apical dominance for the studied species is defined as disappearance of a single trunk at a certain age of the tree followed by its replacement with two or more equipollent trunks or branches. Disappearance of the apical dominance significantly changes the shape of the arboreal crown. For example, undersized trees with spherical crowns are common in the Red Forest. In many cases, the disappearance of apical dominance results in shrinking of the upper part of the tree or the entire tree. Hereinafter the morphoses are defined as manifestations of disappearance of the apical dominance. As a probability of the irradiation effect on the morphological level in a certain dose rate range, an appropriate frequency of detection of morphoses, i.e., the ratio of the number of trees with at least one morphosis in the group of trees representing this dose rate range 
and the total number of trees in this group was used. Obviously, such an approach requires a fairly large experimental volume for each group. In this study, each group contained at least 100 trees, with the exception of the tree group with the highest dose rate. It is important to note that in all cases, regardless of the presence or absence of the morphoses, the dose rates are calculated for the apical meristem of the dominant bud of the trees, i.e. for their normal state, which reflects the assumption that the transformations in the apical system of buds are caused by irradiation. In order to distinguish between the apical meristems of the buds and seed germs (which were also studied), the term upper meristem is applied to denote the apical meristem of the bud.

\section{Identification of dosimetric parameters}

The field studies focused on measuring the parameters required to identify dose rates for the pine trees. First, the absorbed dose rates were measured using RKS-20.03 Pripyat radiometers (manufactured by Energosila, Ukraine. This Geiger-Mueller type radiometer is designed for measurements of absorbed dose rate in the range of $0.1-200 \mu \mathrm{Gy} \mathrm{h}^{-1}$ and beta-particle flux density in the range of $10-2 \times 10^{4} \mathrm{~cm}^{-2} \mathrm{~min}^{-1}$. The device was calibrated and certified by the authorized Ukrainian authority before the measurements). At the Red Forest site with an unevenly distributed contamination, absorbed dose rates were measured in the vicinity of the upper meristem for each tree in the study. At the remaining sites, after assessing spatial distributions of the contamination, averaged external radiation dose rates were identified for groups of the closely located trees.

Second, beta flux $\varphi\left(\mathrm{cm}^{-2} \mathrm{~min}^{-1}\right)$ was measured coming directly from the tree trunk using the RKS-20.03 radiometers for each tree in the study at the Red Forest site. Periodically, samples of stemwood were taken from trees at the Red Forest site and these samples were subsequently measured for incorporated ${ }^{90} \mathrm{Sr}$ and ${ }^{137} \mathrm{Cs}$ in a laboratory. The reason for these measurements was to find a correlation between the radionuclide concentrations measured using standard methods and 
the field measured beta flux values. The beta flux measurement results are influenced by the activity distribution in the trunk near the detector window (all other sources of beta radiation were shielded by the trunk and by the device itself). As it will be shown later, the radionuclide concentrations in bark are several times higher than in stemwood. However, in the relatively young trees of this study the bark was thin and, therefore, the total activity located in bark was much lower than that in the stemwood in the examined volume of the trunk. For ${ }^{90} \mathrm{Sr}$, which is the main contributor to the trees' contamination in the Red Forest, the concentration in stemwood correlates well with that in the bark (see Results). The measurements showed that, for this area and for this instrument, there was a consistent linear dependence of the $\varphi$ value on the ${ }^{90} \mathrm{Sr}$ concentration in the stemwood with the coefficient of $26\left(\mathrm{~Bq} \mathrm{~kg}{ }^{-1}\right)\left(\mathrm{cm}^{-2} \mathrm{~min}^{-1}\right)^{-1}$ with the standard deviation of $8\left(\mathrm{~Bq} \mathrm{~kg}{ }^{-1}\right)\left(\mathrm{cm}^{-2} \mathrm{~min}^{-1}\right)^{-1}$. This made it possible to measure ${ }^{90} \mathrm{Sr}$ concentrations in the stemwood under field conditions without using any expensive or labor intensive radiochemical analyses. Modeling of the particle transport in the tree trunk - radiometer detector system using a Monte Carlo method resulted in the coefficient value that was close to the experimental value (Yoschenko and Bondar 2009), which also demonstrated that the method was reliable.

However, the above described method is only applicable for those conditions when the particle flux from the incorporated radionuclides significantly exceeds particle fluxes from the sources that are considered external relative to a specific tree (e.g. soil and other trees),, which was characteristic of the Red Forest site. At the remaining three sites, the tree contamination levels were fairly low and radiation from the external sources significantly affected the beta flux measurements. Therefore, at those sites, the radioactive contamination values were based on the laboratory measurements of the radionuclide activity in composited samples, each consisting of several subsamples taken from various parts of the tree (e.g. stemwood, inner and outer bark, needles of 1 year 
old and over 1 year old, offshoot branches, buds, and branches) for the groups of closely located trees.

Also, for a small subset of trees at the Red Forest site, tree organs were sampled several times each year over a three-year period to characterize monthly changes in radionuclide activity concentrations. For subsequent use in the newly developed dosimetric model, these dynamics for each radionuclide are represented as unitless $a_{i, j}$ factors (time-dependent radionuclide concentration ratios in tree organs) defined as shown in eqn (1)

$$
a_{i, j}=\frac{C_{i, j}}{C_{w}\left(t_{0}\right)},
$$

where $i$ and $j$ signify the element (organ) of the tree and the time period (month), respectively; $C_{i, j}$ is the concentration of the radionuclide in the $i$ organ during the $j$ period of time; and $C_{w}\left(t_{0}\right)$ is the corresponding value in the stemwood at the baseline moment of time, which was June 1 for this study. For processing the measurement results, a polynomial approximation was used for interpolation of the dependencies for those periods of time when sampling was performed less frequently. The values of these factors were calculated for the middle of the month.

\section{Radionuclide activity measurements}

Prior to laboratory measurements, the samples of each tree organ were dried at $105^{\circ} \mathrm{C}$, crushed, and homogenized. After calcination of an aliquot at $450^{\circ} \mathrm{C}$ for $24 \mathrm{~h}$, the ashes were dissolved in $10 \mathrm{~mL}$ of $6 \mathrm{~N} \mathrm{HNO}_{3}$ and the volume was increased to $50 \mathrm{~mL}$ with distilled water. Obtained solutions were filtered through the "blue ribbon" paper filters, the filters were charred and the ashes were added again to the corresponding solutions. The filtration was repeated until the full dissolving of the material of the samples occurred. The ${ }^{137} \mathrm{Cs}$ activities in the final digests were measured by means of gamma-spectrometry (ADCAM-300 with the GEM-30185 detectors, EG\&G 
ORTEC, USA). The ${ }^{90} \mathrm{Sr}$ activities were measured with a beta-spectrometer SEB-001 (Ukraine) after application of a standard radiochemical procedure to extract ${ }^{90} \mathrm{Sr}$ from the samples (Pavlotskaya 1997).

\section{Cytological analyses}

The studies of radiation induced defects utilized a direct count of aberrations in the meristem cells of seeds, germs, and Single Cell Gel Electrophoresis assay (known as the Comet assay) for upper meristem cells (bud tissues). An attempt to apply a direct count to the upper meristem cells did not deliver valid results due to low mitotic activity.

For these analyses, several model trees were selected from each site with average development parameters from various dose rate groups, so that those trees consistently represented the entire dose rate range. For the Comet assay, each dose rate group was represented by two trees, with and without the morphosis.

In November of 2006 and 2007, all pinecones that reached a certain phase of development from the model trees were collected. The pinecones were stored in dry conditions until a so called "spring draught" period started, i.e., until the pinecones opened and the seeds easily separated from the pinecones. All seeds from each tree were collected. The methods described in Geraskin et al. (2003b) were used for this study. The seeds were placed in Petri dishes on a wet cotton wool wad and absorbent paper with an optimal moisture balance and then germinated at $22^{\circ} \mathrm{C}$ under laboratory conditions. When the germs appeared, they were restrained by acetic alcohol (Pausheva 1988). The first mitoses wer observed when the roots were $7-9 \mathrm{~mm}$ long.

The root samples were then dyed using acetocarmine. A tip of the root, $1.5-2 \mathrm{~mm}$ long, was placed into a drop of acetocarmine, the mixture was carefully crushed with a cover glass until 
the bulk of the preparation separated from the base of the root. After being heated over an alcohol lamp for a few seconds, the specimen was ready for microscopic analysis.

Only undamaged cells that were clearly seen in the microscope were analyzed. The total amount of cells, prophases, metaphases, anaphases, telophases, and interphases were determined within the range of vision to identify the mitotic index. On the average, about 10,000 cells were anlayzed of the apical meristem of seed germs for each tree from which the pinecones were collected. The aberration changes of chromatin in the anaphase and telophase cells were identified and the number of aberrations of each type was counted. The percentage of aberrant anaphases, telophases, and anatelophases was considered to be the major quantitative indicator of the irradiation effect. An Axioskop 40 microscope (Carl Zeiss) equipped with a digital camera was used to be able to store the digital pictures in the computer.

The buds for the Comet Assay analysis were sampled in the spring and summer of 2009. The Comet Assay implementation option described in Gichner et al. (2000) was used. To prepare the microscope slides, they were dipped several times into a $1 \%$ solution of agarose with a normal melting point (TopVision Agarose LE \#R0491, Fermentas) in distilled water $\left(50^{\circ} \mathrm{C}\right)$ followed by drying at room temperature. All subsequent operations were performed in a dark room. $400 \mu \mathrm{L}$ of a cold modified Sörensen buffer solution (50 mM of sodium phosphate, $\mathrm{pH}$ 6.8, 0.1 mM EDTA, and 0.5\% DMSO) were introduced into a Petri dish. The bud sample was carefully and thinly sliced using a clean razor blade and the slices were dipped several times in the buffer solution. The Petri dish was placed on ice in a tilt position to make sure that the nuclei flushed from the sample would be collected in the buffer. $45 \mu \mathrm{L}$ of the nuclei suspension were sampled from the Petri dish and introduced into a microscopic vial placed in a thermostat at $37^{\circ} \mathrm{C}$. The same volume of $1 \%$ solution of agarose with a low melting point (TopVision Agarose LM \#R0801, Fermentas) in the phosphate buffer saline solution at $37^{\circ} \mathrm{C}$ was added into the microscopic vial and the mixture was carefully 
stirred. The generated nuclei suspension in $0.5 \%$ agarose solution was transferred onto the pretreated slide using a micro-feeder and covered with a cover glass. The slide covered with the cover glass was held on ice for at least 5 minutes. Then the cover glass was removed and $90 \mu \mathrm{L}$ of $0.5 \%$ agarose solution with a low melting point was introduced onto the slide. The slide was again covered with the cover glass and held on ice for at least 5 minutes. Then the cover glass was removed and the slide was placed into an electrophoresis horizontal tank filled with a freshly prepared buffer solution for cold electrophoresis ( $1 \mathrm{mM} \mathrm{Na} 2 \mathrm{EDTA}$ and $300 \mathrm{mM} \mathrm{NaOH}, \mathrm{pH}>13$ ), so that the buffer level was $2-3 \mathrm{~mm}$ higher than the slide surface. The slides were held in the tank for 30 minutes at $4^{\circ} \mathrm{C}$ for "unwinding" deoxyribonucleic acid (DNA) strands and releasing damage locations. This (alkaline) implementation of this method releases both single and double DNA strand ruptures and alkaline labile DNA sites, therefore, part of the DNA fragments form due to chromosome damage by the aggressive buffer. The electrophoresis was conducted during 30 minutes at $4{ }^{\circ} \mathrm{C}, 32 \mathrm{~V}$ and the current of $200 \mathrm{~mA}$. Upon completion of the electrophoresis, the slides were rinsed three times with $400 \mathrm{mM}$ Tris, $\mathrm{pH} 7.5$ and were stained with $70 \mu \mathrm{L}$ of ethydium bromide (20 $\mu \mathrm{g} \mathrm{mL}^{-1}$, MO Bio Laboratories Inc.) for 5 minutes. The slides were then dipped in ice cold water to remove the excess ethidium bromide and covered with a coverslip.

The slides were then covered with cover glasses and analyzed in the fluorescent mode in the Axioskop 40 microscope using an appropriate filter.

For each sample, up to a hundred clear images of the "comets" were obtained. For each "comet", the following parameters that quantitatively characterized the extent of the nucleus damage were identified:

- HeadDNA is a percentage of the DNA material remaining in the nucleus after the electrophoresis;

- TailDNA is a percentage of the DNA material that migrated from the nucleus; 
- TailMoment (TM) is the product of the TailDNA and the "comet" tail length in pixels; and

- OliveTailMoment (OTM) is the product of the TailDNA and the distance in pixels between the mass centers of the nucleus and the tail.

The first two parameters were determined using the total luminosity in the image pixels representing the nucleus, tail, and the entire "comet" based on a linear dependence of the image representing the nucleus on the quantity of chromatin in a corresponding point of the slide. The last two characteristics significantly depended on the conditions of the electrophoresis (field intensity, current, duration, thickness of the agarose layer on the slides, etc.). Even under the fixed conditions for the neighboring slides, the direction of the "comet" tails occasionally differed, demonstrating an uncontrolled spatial variability of the electric field within one tank. Therefore, the TM and OTM values for building dose/effect curves were not used. As an irradiation effect, the percentage of cells with the TailDNA exceeding a certain threshold value (e.g., established as the average value for the control site) was considered.

\section{Statistical analysis of the experimental data}

For the analysis of the experimental data, a standard set of MS Excel@ tools was used to determine average values, standard deviations, and correlation coefficients. In the results showing the frequency of radiation effects as a function of the dose rate, the uncertainty on the $\mathrm{X}$-axis included a standard deviation of the dose rate value for the reference point of the apical meristem and standard deviation values for the dose rates for a group of trees representing a certain range of the dose rates. The average value of the dose rate for each group of trees was considered to correspond to the frequency of the radiation effect in the group. For cytogenetic effects, the uncertainty on the Y-axis included a standard deviation of the array of individual values of 
frequency of aberrant cells for trees in one group or a standard deviation of the array of individual values of the radiation effect determined by using the Comet Assay analysis.

\section{RESULTS}

\section{Distribution and dynamics of radionuclide content in the tree organs}

The time-dependent radionuclide concentration ratios in tree organs expressed in terms of $a_{i, j}$ factors based on three years of observations are given in Tables 1 and 2 . The ${ }^{90} \mathrm{Sr}$ concentrations are approximately similar in stemwood, buds, and young needles for most of the year. Much (by a few factors) higher concentrations (as compared to stemwood) were found in other tree organs, with the highest concentrations being found in 2 year old needles and inner bark. Two peaks of activity were observed in the spring and early fall. The second peak in stemwood and branches is slightly "late" occurring in October. For all organs, the seasonal variations of ${ }^{90} \mathrm{Sr}$ concentration were by factors of 2 or 3.

The lowest relative ${ }^{137} \mathrm{Cs}$ contamination was found in the stemwood. On the average, the stemwood contamination is by an order of magnitude lower than contamination of young organs (needles, offshoot branches, buds, and inner bark) and bark. Significant variations of ${ }^{137} \mathrm{Cs}$ concentration were observed in all organs (from a few times to an order of magnitude). As for ${ }^{90} \mathrm{Sr}$, the authors observed the spring and fall maximums of the ${ }^{137}$ Cs concentration, with the exception of offshoot branches and young needles for which the second maximum was observed in summer. The ${ }^{90} \mathrm{Sr} /{ }^{137} \mathrm{Cs}$ concentration ratio in the stemwood for the time $t_{0}$ for the trees sampled in the Red Forest was 17.5. 


\section{Dosimetric model}

The major external radiation source for the trees is associated with radionuclides localized in soil (for the most part, with ${ }^{137} \mathrm{Cs}$ since ${ }^{90} \mathrm{Sr}$ beta radiation is effectively absorbed by soil, while activities of other ChNPP release radionuclides are negligibly small). The ${ }^{137} \mathrm{Cs}$ gamma radiation from all sources (soil and trees) is relatively homogenous in the Yaniv, Kopachi, Ivankiv sites but less so in the Red Forest sampling site. The contribution of the external radiation to the overall dose rate to the trees was identified by direct measurement of absorbed dose rates in the locations where the trees grew.

Accounting for beta radiation from the radionuclides incorporated in the trees required formalization of the task using a conceptual approach. Part of the beta radiation from the radionuclides localized in the target organ (in this article the target organ is the central bud of the upper meristem and dose rates are calculated for a control point in the center of the base of this bud) and localized in adjacent source organs (lateral buds, upper part of the trunk, needles, and lateral offshoot branches) can reach a selected point in the target organ. Therefore, a microdosimetric approach was utilized to solve this problem. To avoid inaccuracies associated with various empirical dose functions, the selected approach was based on using tabulated dose function values

$\operatorname{DRPS}(x)$ (presented in $\mathrm{nGy}(\mathrm{Bq} \mathrm{h})^{-1}$ ) for the point radiation source obtained by the Monte Carlo method (Cross et al. 1992).

Therefore, the dose rate $\left(D H, \mathrm{nGy} \mathrm{h}^{-1}\right)$ calculations for the case when the source organ is also a target organ are performed by integrating the $\operatorname{DRPS}(x)$ values for the organ volume. A cylindrical system of coordinates is considered appropriate here and the maximum beta particles range in the organ has to be accounted for selection of the integration limits to reduce the integration area as shown in eqn (2): 


$$
D H=\rho \times \iiint A(r, z) \times D P R S\left[\sqrt{(r-\xi \times \cos \phi)^{2}+(\xi \times \sin \phi)^{2}+(z-\zeta)^{2}}\right] \times r d r d \phi d z
$$

where $r, z, \phi, \xi$ и $\zeta$ are the coordinates in the cylindrical system of coordinates, cm;

$A(r, z)$ is a function providing a radial and longitudinal distribution of the activity concentration in the organ, $\mathrm{Bq} \mathrm{g}^{-1}$; and

$\rho$ is the density of the matter in the organ, $\mathrm{g} \mathrm{cm}^{-3}$.

The observations resulted in the following assumptions regarding geometric parameters of the upper meristem of the pine trees. The bud system consists of one central (dominant) bud and seven lateral buds. The length of the lateral bud is one-half the length of the central bud at any moment of year. In addition, during one year, the shape of the buds remain the same, and only their size changes. The shape of the buds is described by the dependence between the point radius shape(z) on the surface of the bud and the height $z$ in the cylindrical system of coordinates (with the bud centerline being the vertical axis of the system) as provided in eqn (3):

$$
\operatorname{shape}(z)=L / \text { aspect } \times \cos \left[(z-\text { shift } \times L) \times \frac{\pi}{2 \times(1-\text { shift }) \times L}\right],
$$

where $L$ is the height of the bud, cm,

and the aspect and shift parameters are 6 and 0.2 , respectively.

Based on observations of trees in the study, it was assumed that the radius of the lateral bud is one-half the radius of the central bud, and the concentrations of the radionuclides in the lateral buds is 1.5 times higher than the concentrations in the central bud. The radius of the central offshoot branch (top of the trunk) is equal to the sum of the radius of the central bud and the diameter of the lateral bud. The diameters of seven lateral offshoot branches are assumed to be equal and they are one-half the diameter of the central offshoot branch. There are 10 needles, $5 \mathrm{~cm}$ long each, for every $1 \mathrm{~cm}$ of the length of the central offshoot branch. Based on field observations, the assumed angle between the lateral offshoot branches and the trunk was $25^{\circ}$, and the fact that they absorb radiation 
was ignored (such simplification leads to overestimation of their contribution to the total dose rate but this contribution is several orders of magnitude lower than the contribution of buds). The dose coefficient from needles on the lateral offshoot branches is equal to the dose coefficient from the lateral offshoot branches since geometric parameters of the radiation transfer are similar. The dose coefficient is defined as the dose rate generated by a radionuclide in the control point of the target organ if this radionuclide is incorporated in the source organ with a concentration of $1 \mathrm{~Bq} \mathrm{~kg}^{-1}$. The integral dose coefficient corresponds to the dose rate, considering all source organs, with the concentration of radionuclides in the stemwood also being $1 \mathrm{~Bq} \mathrm{~kg}^{-1}$, i.e. the relationships between the concentrations (eqn (1) and Tables 1 and 2) are taken into account.

The dose coefficients from the radionuclides localized in the trunk and buds are calculated for the control point using eqn (2) within the limits of integration for the segment of the trunk and within the limits established by eqn (3) for the buds. Calculations of the dose coefficients for radionuclides incorporated in offshoot branches and needles should take into consideration air gaps between the source of radiation and the control point. Beta radiation absorption in the air is ignored, but geometric factors of scattering are taken into account. Fig. 1 shows a baseline schematic that remains unchanged for needles of the central and lateral offshoot branches, and only geometric parameters of the calculations change. Absorption of radiation in the central offshoot branch and buds for the $x_{1}$ distance to the point for which the dose coefficient is calculated and scattering in the air gaps $\left(x-x_{1}\right)$ of this radiation system are accounted for. The calculations were performed for all the needles of the central offshoot branch that contributed to irradiation of the given point (for the needles located at large distances $d$ absorption in tissues of the central offshoot branch is complete if $x_{1}$ exceeds the maximum range of beta particles of this radionuclide. For example, for ${ }^{90} \mathrm{Y}$ that has the highest radiation spectrum energies among all studied radionuclides, this value will be about 1 $\mathrm{cm}$. This means that, if the radius of the central offshoot branch is $0.5 \mathrm{~cm}$, contribution to the 
irradiation of those needles for the tips of which the angle $\beta>60^{\circ}$ can be ignored. The major equation for the designations provided in Fig. 1 is provided in eqn (4):

$$
D H(d)=a L \times \int_{0}^{L} \frac{D R P S\left[R \times \frac{\sqrt{(R+I \times \sin \alpha)^{2}+(d-I \times \cos \alpha)^{2}}}{R+I \cdot \sin \alpha}\right]}{(R+I \times \sin \alpha)^{2}+(d-I \times \cos \alpha)^{2}} d l,
$$

where $d$ is the distance between the top of the central offshoot branch and point where the needle is located (Fig. 1);

$R$ is the radius of the central offshoot branch, $\mathrm{cm}$;

$L$ is the length of the needle (or lateral offshoot branch), $\mathrm{cm}$;

$l$ is an integration variable; and

$a L$ is the radionuclide activity per unit of the needle length, $\mathrm{Bq} \mathrm{cm}^{-1}$.

The equation for irradiation from the lateral offshoot branch is similar and only values of the specific parameters change.

Eqns 2, 3, and 4 make it possible to calculate individual dose coefficients for the selected control point within the upper meristem; i.e., values for fixed geometric parameters of the system. The next step is to account for ratios between concentrations of radionuclides in the source organs identified in empirical observations over time (Tables 1 and 2) and the geometric sizes of these organs that correspond to these observations. Therefore, total dose coefficients were determined for each interval of time (month) during one year that corresponds to the concentration of radionuclides in the stemwood (the time $t_{0}$ concentration was set equal to $1 \mathrm{~Bq} \mathrm{~kg}^{-1}$ ). According to the completed calculations, radionuclides incorporated in buds and the main offshoot branch have the most significant contribution to irradiation of the control point, while radiation from other organs can be ignored. The integral (annual) dose coefficient is the sum of the monthly dose coefficients. It is equal to the dose absorbed in the control point of the upper meristem during the year assuming the 
concentration of the radionuclide in the stemwood at $t_{0}$ is $1 \mathrm{~Bq} \mathrm{~kg}^{-1}$. Calculated values of the integral dose coefficients are $6.2\left(\mu \mathrm{Gy} \mathrm{y} \mathrm{y}^{-1}\right)\left(\mathrm{Bq} \mathrm{kg}^{-1}\right)^{-1}$ for ${ }^{90} \mathrm{Sr}$ and $18.1\left(\mu \mathrm{Gy} \mathrm{y}{ }^{-1}\right)\left(\mathrm{Bq} \mathrm{kg}^{-1}\right)^{-1}$ for

${ }^{137} \mathrm{Cs}$. Considering the ratios of the concentrations of other radionuclides at $t_{0}$, for the trees in the Red Forest, the integral dose coefficient is equal to $\left.7.2(\mu \mathrm{Gy} \mathrm{y})^{-1}\right)\left(\mathrm{Bq} \mathrm{kg}^{-1}\right)^{-1}$ if calculated based on ${ }^{90} \mathrm{Sr}$.

\section{Dose rates for trees}

The dose rates for the upper meristem of the trees included in the sampling plan were calculated for 2006. For the trees at the control site near the town of Ivankiv, this dose rates were $4.5 \mathrm{mGy} \mathrm{y}^{-1}$ with a the standard deviation of $0.5 \mathrm{mGy} \mathrm{y}^{-1}$ (Fig. 2). Internally incorporated ${ }^{137} \mathrm{Cs}$ significantly contributes to the dose rates. In general, the internal irradiation contributes up to $2 / 3$ of the total dose rate. In spite of the well-defined ChNPP component, the total dose rates are fairly low and the selection of this site as a control site appears justifiable especially due to the sensitivity of the studied species to soil and climatic conditions.

At the Yaniv site, dose rates are by an order of magnitude higher (Fig. 2). They range from 2.5 to $4.8 \mathrm{cGy}^{-1}$ with the internal irradiation sources dominating. At the Kopachi site, the dose rates are of the same order, being equal to $1.9 \pm 0.3 \mathrm{cGy}^{-1}$, and the contribution of the external irradiation sources is $2-3$ times higher than that of the internal irradiation sources.

At the Red Forest site, radiation from the incorporated ${ }^{90} \mathrm{Sr}$ prevails in the total irradiation of the upper meristem. The dose rates vary widely, from several cGy $\mathrm{y}^{-1}$ to several Gy $\mathrm{y}^{-1}$ (Fig. 2), and the contribution of the internal irradiation increases with an increase in the total dose rate. The dose rate of several Gy $\mathrm{y}^{-1}$ that is characteristic of most of the trees at the Red Forest site is a relatively high value, resulting in a high frequency of radiobiological effects in the Red Forest, even on the morphological level. 
However, during their lifetime, the studied species were exposed to chronic irradiation, and the effect/dose ratios shown below characterize their cumulative effect, i.e., the effect implemented in each group of trees during the entire period of irradiation with the certain dose rate calculated at the beginning of the studies (2006). The dose rates during the study changed due to a number of factors, such as radioactive decay of radionuclides, changes in their bioavailability resulting from dissolution of the fuel particles that were part of the fallout contamination, sorption of the radionuclides by soil particles, and radionuclide transport in soils (Fig. 3). The retrospective assessment of the dynamics of the dose rates over time is a large scale task that goes beyond the scope of these studies. However, these dynamics were evaluated separately, taking these factors into account (Yoschenko et al. in press). In general, these separate studies showed that during the initial period of existence of the trees (2 -5 years after the ChNPP accident), their dose rates might have exceeded the current dose rates by factors of $2-3$, and the obtained dynamics of this value are consistent with other experimental data (Kozubov and Taskaev 2002).

\section{Morphological effect vs. dose rate}

The obtained frequency of morphological changes (disappearance of the apical dominance) as a function of the dose rate is provided in Fig. 4. The ranges of the combined standard deviations for each group take into account the uncertainties associated with the tree contamination and the ranges of the calculated dose rate values for each of the tree groups.

From Fig. 4, the dose rate values at which morphological changes are observed in $10 \%$ and $50 \%$ of the trees are about $0.008 \mathrm{~Gy} \mathrm{y}^{-1}$ and $0.35 \mathrm{~Gy}^{-1}$, respectively, or about $0.9 \mu \mathrm{Gy} \mathrm{h}^{-1}$ and 40 $\mu \mathrm{Gy} \mathrm{h}^{-1}$. On the whole, the function has a classic sigmoid shape with the area of the initial growth at the dose rates ranging from low values to approximately $1.5 \mathrm{~Gy}^{-1}$ followed by approaching $100 \%$ frequency of occurrence of the effect at higher dose rates. From the practical standpoint, this fact is 
very significant because dose rates around $1.5 \mathrm{~Gy}^{-1}$ can occur in a large area of the Red Forest interim radioactive waste storage facility (Fig. 2) as well as in some other areas of the ChEZ. A high frequency of morphological changes triggers questions on the future fate of pine trees in such territories.

The described dependence characterizes a cumulative radiation effect for Scots pine trees of about 18 years old upon completion of the studies, i.e., the effect that implemented in each group of trees during the entire period of their irradiation at a certain dose rate calculated for the period of the studies. It should be noted that the age of the trees in the study precludes a possibility of their irradiation at unknown doses during the acute phase of the ChNPP accident; therefore, the focus was specifically on the effect of their chronic irradiation.

The probability of morphoses at all experimental sites changes with age of the tree. The first morphoses were the most common for trees of $4-8$ years old, and their first occurrence in older trees became more and more infrequent, almost non-existent by the time of the studies. For the entire study, the average age of the first occurrence of the morphoses was about 5.2 y with the standard deviation of $2.6 \mathrm{y}$.

The dynamics of the effect formation (defined as its first occurrence in each tree) were analyzed for groups the trees representing various dose rate ranges (Fig. 5). The realization of effect values for a certain age and dose rate group were calculated as a ratio of the morphoses frequency in this age and the morphoses frequency at $18-19$ years old, the age of completion of an intense formation of new morphoses.

An active occurrence of the first morphoses finishes when the trees reach the age of about $10 \mathrm{y}$, and variations of the overall dynamics for various dose rate groups are insignificant. The exception is the dose rate group of $0.0379 \mathrm{~Gy}^{-1}$ that combines the trees at the Yaniv and Kopachi sites. For this dose rate group, it was observed that morphoses occured slightly later at the Kopachi 
site. There is a weak trend for an earlier occurrence of morphoses at higher dose rates. It is also interesting to note that the values for the control Ivankiv site $\left(0.0111 \mathrm{~Gy}^{-1}\right.$ group) almost completely coincide with the corresponding average values of the entire array. Consequently, it can be assumed that the difference of the Kopachi site is due to a different factor, but not radiation.

The averaged dynamics of the effect formation can be satisfactorily approximated by a logarithmically normal dependence with the average geometric value of $4.4 \mathrm{y}$ with the geometric standard deviation of $1.6 \mathrm{y}$ (the dashed line in Fig. 5). Therefore, it is possible to assume that the formation of the effect (morphological changes) in during the study is a random process described by the above mentioned probability distribution law and it somewhat depends on the irradiation value. The irradiation value only determines the final value of the effect implemented for the certain dose rate group.

\section{Cytogenetic effects in germs versus dose rate}

The results of the completed cytological analyses of the seed germs for the sampled trees are given in Table 3. The mitotic index ranges from 60 to 80 . The dominating cytogenetic effect is associated with fragments of the chromosomes that account for $70-99 \%$ of all defects regardless of the dose rate for the upper meristem shown in the first column of the table.

Large quantities of the cytogenetic effects were found in telophase. In general, defects were effectively detected only in anaphase and telophase. The average occurrence of the effect for each dose rate group; i.e., for several trees with close dose rates were calculated (Fig. 6). It should be reemphasized that the dose rates were calculated for the upper meristem, and not for the seeds; therefore, the obtained function shown in Fig. 6 is not a rigid function.

It has been observed that the effect occurrence increases with an increase of the dose rates for the upper meristem, although the growth varies in different parts of the range. Unlike the 
function for the morphological effects, the curves do not reach the asymptomatic levels even at the highest dose rate levels. It is possible to assume that not all defects can be visually detected in the anaphase since, on the whole, the percentage of the defects is lower in the anaphase than in the telophase. There are only a few individual aberrant cells in each tree in the anaphase while there are a few dozen of them in the telophase.

\section{Cytogenetic effects in the tissues of the upper meristem versus dose rate}

The observed effects of radioation in the organ that is considered responsible for formation of morphological changes on the macro-level and for which the dose rates were calculated were determined by a direct comparison of individual (for each "comet") dose rates or average TailDNA values for a dose rate range with the dose rates for the upper meristem of the sampled trees. However, a significant argument against using this approach is associated with a generally high release of the DNA material outside the nucleus, even at the control site where it reached, on the average, $51.3 \%$ with the standard deviation of $19.7 \%$. At the same time, significant deviations of the individual TailDNA values from the average value were only observed for several "comets" at the control experimental site. Therefore, the average value can be considered an indicator of the medium level of the DNA defects resulting from background radiation, other natural factors, and impact of the chemicals used in the analytical method on the nuclei. Additional radiation creates an additional number of defects in the specific nucleus and the "comet" tail has to include a higher than average quantity of chromatin.

Therefore, the study only considered the fractions of those nuclei ("comets") (selected from their total number for a certain dose range) as a function of dose rate for which a more massive impact is observed; i.e., when the TaiDNA value exceeds the stated average background level of the DNA damage. To have a complete picture, the TailDNA level that was considered the background 
level (hereinafter shown as $v$ ) varied. Beyond that, the effect as a function of dose rate was identified separately for trees with and without morphoses. The analytical results are shown in Fig. 7. As in the previous section, the $\mathrm{X}$-axis shows dose rate values at the time of the measurements.

For the trees with morphoses, the cytogenetic effect (a fraction of nuclei with massive defects) in the upper meristem increases with an increase of the dose rate (Fig. 7a). With an increase of the $v$ value, the dependence transforms from a close to sigmoid shape to an almost linear shape. The total picture misses points representing the group of $7.3 \mathrm{~Gy}^{-1}$, which is due to an insufficient amount of the "comets" analyzed for the given group (represented by a small number of trees). No effect vs. dose rate dependence was observed for trees without morphoses (Fig. 7b). The shapes of dependencies for the cytogenetic effects in germs and the upper meristem at the average $v$ values were similar (Figs. 4 and 7a).

\section{DISCUSSION}

The online database for the project entitled "Radiation Effects on Terrestrial Plants" (EPIC 2009) contains data on the radiation effects for terrestrial ecosystems, including coniferous forests of the ChEZ. According to this database, the chronic irradiation dose rates ranging from $5 \times 10^{-4}$ to $5 \times 10^{-3} \mathrm{~Gy} \mathrm{~d}^{-1}$ result in cytogenetic effects, increase of morphological variability, and suppression of viability of the seeds, which, in principle, is consistent with the functions shown in Figs. 4, 6, and 7. However, these studies show that a noticeable increase of occurrence of both morphological and cytogenetic changes results from the lowest dose rates.

It should also be noted that the Predicted No Effect Dose Rate (PNEDR) value of $10 \mu \mathrm{Gy} \mathrm{h}^{-1}$ for terrestrial ecosystems applied in the ERICA (2007) Project corresponds to the presence of morphoses in about $35 \%$ of the sampled trees (Fig. 4). As the effect for the terrestrial ecosystems, 
most of the literature describes changes that may result in degradation or even death of the ecosystem. However, it is difficult to say how critical even a massive disappearance of apical dominance will be for the studied ecosystems. For example, the Red Forest has a very high occurrence of morphoses, but trees do not die there frequently. On the other hand, in most cases, disappearance of apical dominance suppresses growth of trees, which may provide advantages for less radio sensitive species (specifically, deciduous species in mixed forests), thereby shaping the evolution of the ecosystem.

The frequencies of occurrence of aberrant cells in the root meristem of the pine tree seed germs shown in Fig. 6 are much higher than those obtained earlier (Geraskin et al, 2003 b) for two populations of ordinary pines from the ChEZ. However, this comparison may not appear adequate since the results were obtained at different times and at different sites, and, beyond that, these other species of pine existed when the ChNPP accident took place and, therefore, they underwent acute irradiation that might have initiated protective mechanisms. For cytogenetic defects at similar doses absorbed during the vegetative period, the Fig. 6 data are more consistent with the data for cells in the meristem of leaves in agricultural plants (Geraskin et al. 2003a).

On the whole, it is possible to assume that the above mentioned differences can be associated with differences in the methodological approaches for the dose assessments (specifically, using soil contamination data to calculate the concentrations of incorporated radionuclides and external irradiation dose rates and the selection of tree organs for which the doses are calculated).

A simultaneous morphological and cytological study of the irradiation effects using the same sampling plan makes it possible to establish connections between the effects on different levels. At first sight, morphological changes in the upper meristem and cytogenetic effects in the seed germs can be associated with various dose rates for the upper meristem and seeds. Therefore, 
these events can only be related by assuming that they result from the same genetic factor expressed in all levels of the organism. However, this assumption does not have any a priori justification.

To search for a correlation between the frequencies of morphological changes in the upper meristem and cytogenetic defects in cells of the seed germs, each experimentally obtained value of the cytogenetic effect in the anatelophase (Fig. 6) was correlated with the value of the morphological effect of irradiation at the given dose rate obtained by a linear interpolation of the function shown in Fig. 4. A linear correlation was established that relates the observed effects (Fig. 8). The linear correlation is applicable only in a certain range because the frequency values are not able to exceed $100 \%$ and the actual shape of the correlation curve is likely to be sigma-like. Therefore, the fact that cytogenetic effects in seeds; i.e., inherited stochastic effects, can be related to morphological changes in the upper meristem is indicated. The only point that is quite inconsistent with this was found at the Kopachi site. The frequency of morphoses for trees at the Kopachi site is almost twice as low as we could have expected taking into account the frequency of cytogenetic defects. In this respect, it is appropriate to mention that a certain delay was observed in formation of morphological effects at the Kopachi site as well (Fig. 5).

Using a similar approach, a correlation between the cytogenetic effect in the cells of the upper meristem and the frequency of morphoses observed at certain dose rates in trees with morphoses was investigated. For this investigation, the $7.3 \mathrm{~Gy}^{-1}$ point (Fig. 7) was not considered because the validity of the cytological analysis results for this tree was questioned. At the $v$ value being equal to $75 \%$ and $80 \%$, the correlative function was close to a linear function (Fig. 9a and 9b) while at higher $v$ values, it transforms into a sigmoid function (Fig. 9c and 9d).

Therefore, the frequency of morphoses in Scots pine is well correlated with the cytogenetic effect of irradiation in both seed germs and cells of the upper meristem. The shape of dependence of the frequency of morphological changes on the dose rate makes it possible to assume that the 
cytogenetic effect results from the stochastic effect of irradiation. The presence of correlation between the frequency of morphoses and the cytogenetic effect demonstrates that this effect takes place on a cellular level or that the effect (root cause of the morphological changes) is related to the cytogenetic effect described. The dynamics of frequency of morphological changes were similar for all groups of trees and did not depend on the dose rate for the upper meristem. It was observed that cytogenetic effects in cells of both upper meristem and seed germs occurs without any significant increase of a number of morphoses. It would be reasonable to assume that morphoses are most likely to happen in young trees due to certain physiological reasons (especially due to qualitatively analogous dynamics at the control site).

The effect initiating morphoses has to be related to the time when the frequency of morphoses drastically increased. Such effects can be related to genetic changes resulting in disappearance of the apical dominance or death of cells of the dominant bud responsible for its growth. Probabilities of both effects will be proportional to the frequency of cytogenetic defects in the cells of the upper meristem. However, death of cells as a cause of suppression of the dominant bud appears to be significantly less probable due to a large number of currently observed cytogenetic defects and absence of new moprhoses. This hypothesis can also be substantiated by a high frequency of morphoses in young pine trees growing in relatively lightly contaminated areas of the ChEZ that originated $7-10$ years after the ChNPP accident due to self-seeding from the forests existing at the time of the accident and exposed to high radiation doses during the acute phase of the accident. The authors can conclude that the original cytogenetic changes had not disappeared a few years before the seeding, and were transferred to the genetic material.

In addition, the frequency of cytogenetic defects in trees with morphoses (Fig. 7a) depends on the dose rate. This dependence can be observed with a relatively small number of analyses since defects in this case are mostly point defects that do not cause death of cells. The point defects are 
inherited and released if impacted by aggressive media, thereby generating "comets" with high TailDNA values. The dependence is observed in the studied material because it contains a large number of cells with such defects. At the same time, cells of the upper meristem without morphoses contain cytogenetic defects resulting from irradiation of these particular cells (Fig. 7b). In this case, higher dose rates will cause higher levels of defects, but the experimentally obtained dependence may be "blurred" due to random factors if the number of studied "comets" is insufficient.

Therefore, genetic reasons for formation of morphoses appear plausible. However, it should be noted that the above mentioned considerations regarding the mechanism for the observed effect of chronic irradiation of Scots pine are based on indirect observations and more detailed cytogenetic studies are required to either confirm or deny them.

\section{CONCLUSIONS}

In this study, quantitative dose rate/effect correlations were established for morphological and cytogenetic changes in Scots pine trees exposed to chronic irradiation. Dose rates of $0.9 \mu G y \mathrm{~h}^{-1}$ and $40 \mu \mathrm{Gy} \mathrm{h} \mathrm{h}^{-1}$ caused disappearance of the apical dominance in $10 \%$ and $50 \%$ of the sampled trees, respectively. This morphological effect and related suppression of development can, to a certain extent, affect evolution of specific ecosystems in the ChEZ, which, possibly, has to be taken into consideration for establishment of the predicted, no effect dose rate values and similar values for terrestrial ecosystems. Morphological changes are shown to originally occur when the trees are $4-$ 8 years old, with a weak correlation between dynamics of their occurrence and the dose rate. In addition, a connection was established between cytogenetic changes in cells of the seed germs and the upper meristem and morphological changes in trees. A possible mechanism explaining formation of radiation induced morphoses was proposed based on the major empirical data obtained 
during the studies, which support the assumption that the observed morphological changes result from certain genetic changes in cells of the apical meristem of the Scots pine trees.

Acknowledgments - The authors express their appreciation to the Science and Technology Center in Ukraine (STCU) for funding the studies under Project 3674. The authors would like to thank Ines Triay, Yvette Collazo, Kurt Gerdes, and Ana Han for their support of the U.S. Department of Energy Office of Environmental Management's International Cooperative Program with IRL. The authors would like to express their gratitude to Tatyana Albert (Thomas E. Albert and Associates, Inc.) for translating documents and reports prepared at SRNL and IRL and Elizabeth LaBone for her editorial contributions.

Disclaimer - This manuscript has been co-authored by Savannah River Nuclear Solutions, LLC under Contract No. DE-AC09-08SR22470 with the U.S. Department of Energy. The United States Government retains and the publisher, by accepting this article for publication, acknowledges that the United States Government retains a non-exclusive, paid-up, irrevocable, worldwide license to publish or reproduce the published form of this work, or allow others to do so, for United States Government purposes. Mention of trade names or commercial products does not constitute endorsement or recommendation for use by the authors or their corresponding organizations. 


\section{REFERENCES}

Beaugelin-Seiller K, Garnier-Laplace J, Gariel JC, Jasserand F. E.D.E.N.: A tool for the estimation of dose coefficients for non-human biota. Radioprotection 40(Suppl.1):S921-S926; 2005.

Beresford NA, Balonov M, Beaugelin-Seiller K, Borretzen P, Brown J, Cheng JJ, Copplestone D, Doi M, Gschak S, Golikov S, Horyna J, Hosseine A, Howard BJ, Jasserand F, Kamboj S, Nedveckaite T, Olyslaegers G, Sazykina T, Vives I Batlle J, Yankovich T, Yu C. Models and approaches available to estimate the exposure of non-human biota: An international comparison of predictions. In: The 2nd International Conference on Radioactivity in the Environment. Osteras: NRPA; 2005: 146-149.

Bugai D, Kashparov V, Dewiere L, Khomutinin Yu, Levchuk S, Yoschenko V. Characterization of subsurface geometry and radioactivity distribution in the trench containing Chernobyl cleanup wastes. Environ Geol 47: 869-881; 2005.

Cross WG, Freedman NO, Wong PY. Beta-ray dose distributions from point sources in an infinite water medium. Health Phys 63:160-171; 1992.

Environmental Protection from Ionising Contaminants (EPIC). Deliverable 5. Report on doseeffects relationships for reference (or related) Arctic biota. EPIC database "Radiation effects on biota". A deliverable report for EPIC. Project ICA2-CT-2000-10032 [online]. Available at: http://wiki.ceh.ac.uk/download/attachments/115802239/EPIC_D5.pdf?version=1. Accessed 26 July 2010.

ERICA. D-ERICA: An integrated approach to the assessment and management of environmental risks from ionizing radiation. Contract Number FI6R-CT-2004-5088472007; 2007 [online]. Available at: http://wiki.ceh.ac.uk/download/attachments/115017395/DErica.pdf?version=1. Accessed 26 July 2010.

Fesenko SV, Alexakhin RM, Geras'kin SA, Sanzharova NI, Spirin YeV, Spiridonov SI, Gontarenko IA, Strand P. Comparative radiation impact on biota and man in the area affected by the accident at the Chernobyl nuclear power plant. J Environ Radioact 80:1-25; 2005.

Frolova NP, Popova ON, Taskaev AI. Study of impact of radioactive fallout on natural agrocenoses in the area of the Chernobyl NPP accident. In: Impact on radioactive contamination on terrestrial ecosystems in the area of the Chernobyl NPP accident (1986-1996). Syktyvkar: Komi SC UrD RAS; 1996: 19-37. (in Russian)

Geraskin SA, Dikarev VG, Zyablitskaya YeYa, Oudalova AA, Spirin YeV, Alexakhin RM. Genetic consequences of radioactive contamination by the Chernobyl fallout to agricultural crops. J Environ Radioact 66:155-169; $2003 \mathrm{a}$.

Geraskin SA, Zimina LM, Dikarev VG, Dikareva NS, Zimin VL, Vasiliyev DV, Oudalova AA, Blinova LD, Alexakhin RM. Bioindication of the anthropogenic effects on micropopulations of Pinus sylvestris, L. in the vicinity of a plant for the storage and processing of radioactive waste and in the Chernobyl NPP zone. J Environ Radioact 66:171-180; 2003b.

Gichner T, Ptacek O, Stavreva DA, Wagner ED, Plewa MJ. A comparison of DNA repair using the comet assay in tobacco seedlings after exposure to alkylating agents or ionizing radiation. Mutat Res 470:1-9; 2000. 
Grodzinsky DM, Bulakh AA, Gudkov IN. Radiobiological effects in plants. In: Baryakhtar VG ed. Chernobyl Catastrophe. Kyiv: Naukova dumka; 1995: 293-310. (in Russian)

International Commission on Radiological Protection. A framework for assessing the impact of ionizing radiation on non-human species. Oxford: Pergamon Press; ICRP Publication 91, Vol. 33 No 3; Ann ICRP; 2003.

Kal'chenko VA, Arkhipov NP, Fedotov IS. Mutagenesis of ferment locusts induced in Pinus sylvestris $L$. spores by ionizing irradiation associated with the ChNPP accident. Genetika 29:266-273;1993a.

Kal'chenko VA, Rubanovich AV, Fedotov IS, Arkhipov NP. Gnetic effects induced by the ChNPP accident in sexual cells of Pinus sylvestris L. Species. Genetika 29:1205-1212; 1993 b.

Kashparov VA, Lundin SM, Khomutinin YV, Kaminsky SP, Levchuk SE, Protsak VP, Kadygrib AM, Zvarich SI, Yoschenko VI, Tschiersch J. Soil contamination with 90Sr in the near zone of the Chernobyl accident. J Environ Radioact 56:285-298; 2001.

Kashparov VA, Lundin SM, Zvarych SI, Yoshchenko VI, Levchuk SE, Khomutinin YV, Maloshtan IM, Protsak VP. Territory contamination with the radionuclides representing the fuel component of Chernobyl fallout. Sci Total Environ 317:105-119; 2003.

Kozubov GM, Taskaev AI. Radiobiological studies of coniferous species in the area of the ChNPP accident. Moscow: Design.Information.Cartography; 2002. (in Russian)

Oudalova A, Geras'kin S, Vasiliev D, Dikarev V. Cytogenetic variability in Pinys sylvestris L. populations experiencing anthropogenic influence. Radioprotection 40(Suppl.1):S223-S228; 2005.

Pausheva ZP. Practical course on on plants cytology. Moscow: Agropromizdat; 1988. (in Russian)

Pavlotskaya FI. Main principles of radiochemical analysis of the environmental objects and methods of measurements of strontium and transuranium elements radionuclides. Journal of Analytical Chemistry 52:126-143; 1997. (in Russian)

Pozolotina VN. Long-term consequences of radiation impact on plants. Ekaterinburg: Akademkniga; 2003. (in Russian)

Rubanovich AV, Kal'chenko VA. Violation of segregation in chronically radiated Pinus sylvestris $L$. populations growing in the area of the ChNPP accident. Genetika 30:126-128; 1994.

Shevchenko VV, Grinikh LI. Cytogenetic effects in Crepis tectorum populations growing in the Bryansk Region 7 yeras after the ChNPP accident. Radiats Biol Radioecol 35:720-725; 1995.

The EMRAS Biota Working Group. Review of the selection criteria used by different biota dose assessment models in the selection of reference organisms [online]. Available at: http://www-ns.iaea.org/downloads/rw/projects/emras-biota-ref-organisms.doc. 26 July 2010.

USDOE. A graded approach for evaluating radiation doses to aquatic and terrestrial biota. Washington, DC: USDOE; Technical Standard DOE-STD-1153-2002; 2002.

Yoschenko VI, Bondar YuO. Dose dependence of the frequency of morphological changes in Scots Pine (Pinus sylvestris L.) in Chernobyl exclusion zone. Radiats Biol Radioecol 49:117-126; 2009. 
Yoschenko VI, Kashparov VA, Levchuk SE, Bondar YuO, Lazarev NM, Yoschenko MI. Effects of chronic irradiation of Scots pine (Pinus sylvestris L.) in Chernobyl exclusion zone. Radiats Biol Radioecol (In press). 


\section{FIGURE CAPTIONS}

Fig. 1. Baseline schematic for needles of the central and lateral offshoot branches.

Fig. 2. Dose rate distribution in the sampled trees. The dotted lines show the boundaries of the three clusters of sites included in the sampling plan - the Ivankiv (control), Kopachi-Yaniv, and Red Forest sites.

Fig. 3. Dynamics of the normalized dose rate (unitless) from incorporated radionuclides (a) and from external sources (b) for trees from the Red Forest (RF), Kopachi (K), Yaniv (Ya), and Ivankiv (Iv) sites. The dynamics for the trees growing on the trench (T) and outside the trench (OT) are shown for the Red Forest site.

Fig. 4. Effect (probability of morphological changes) as a function of dose rate in Scots pine trees. The dotted line shows the background (control site) value of frequency.. The circles indicate the average dose rates for the tree groups, and the horizontal bold lines correspond to the ranges of the combined standard deviations for each group

Fig. 5. Dynamics of formation of morphological changes in trees from various dose groups (the average dose rates for each group are given in the legend for 1990, Gy $\mathrm{y}^{-1}$ ).

Fig. 6. Effect (probability of cytogenetic changes) as a function of dose rate in seed germs of Scots pine trees. The horizontal lines represent a range of the combined standard deviations for the dose rate of the upper meristem of the given group. An uncertainty of the effect (a standard deviation of the values for a set of trees in each group) is shown by vertical lines only for the anatelophase.

Fig. 7. Effect (probability of cytogenetic changes) as a function of dose rate in the cells of the upper meristem for various $v$ values (\%, given in the legend) for trees with (a) and without (b) morphological changes. 
Fig. 8. Correlation between cytogenetic effect in germs and morphological effect for Scots pine trees.

Fig. 9. Correlation between cytogenetic effect in cells of the upper meristem and morphological effect at $v$ values of $75 \%$ (a), $80 \%$ (b), $85 \%$ (c), and $90 \%$ (d). 


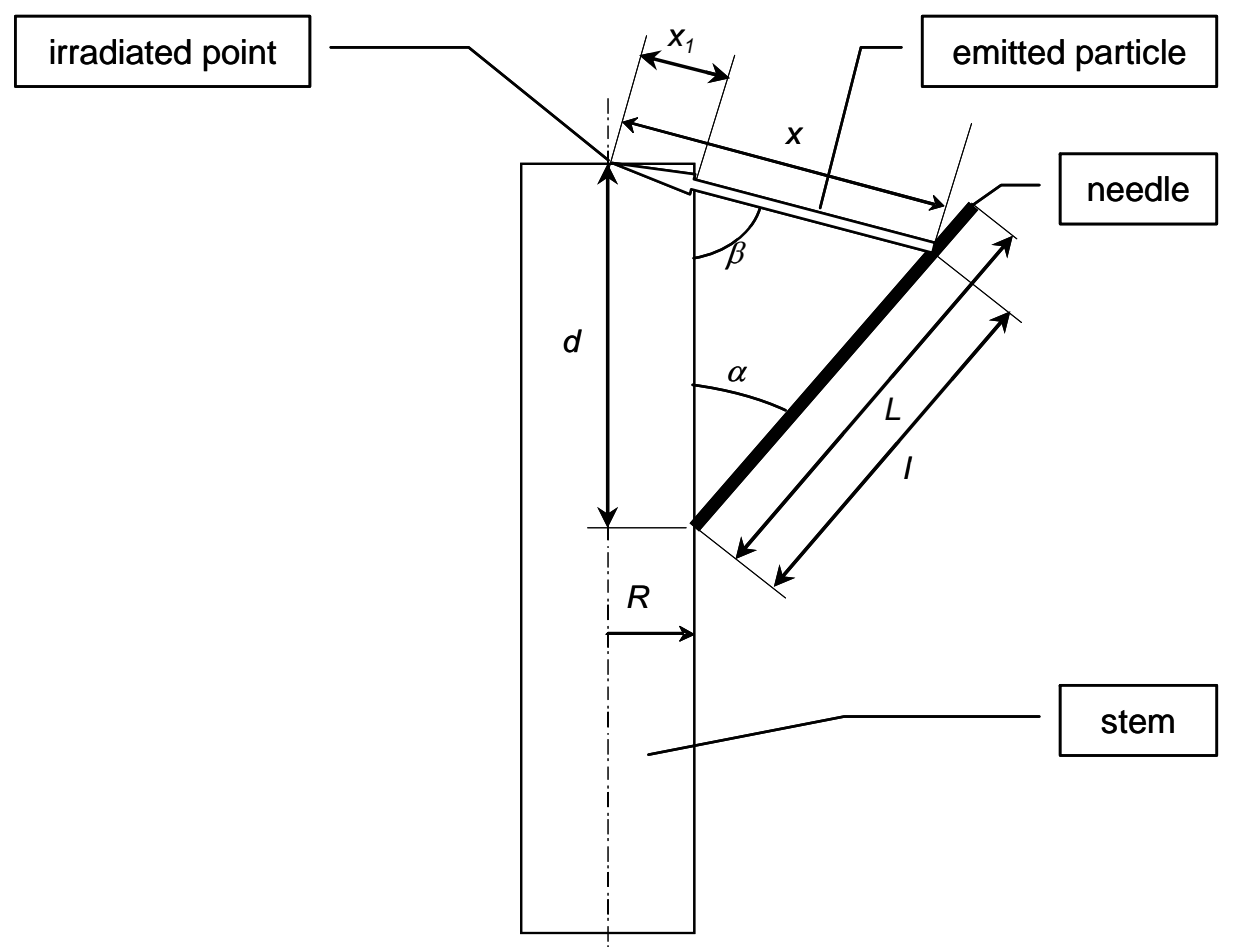

Fig. 1. Baseline schematic for needles of the central and lateral offshoot branches. 


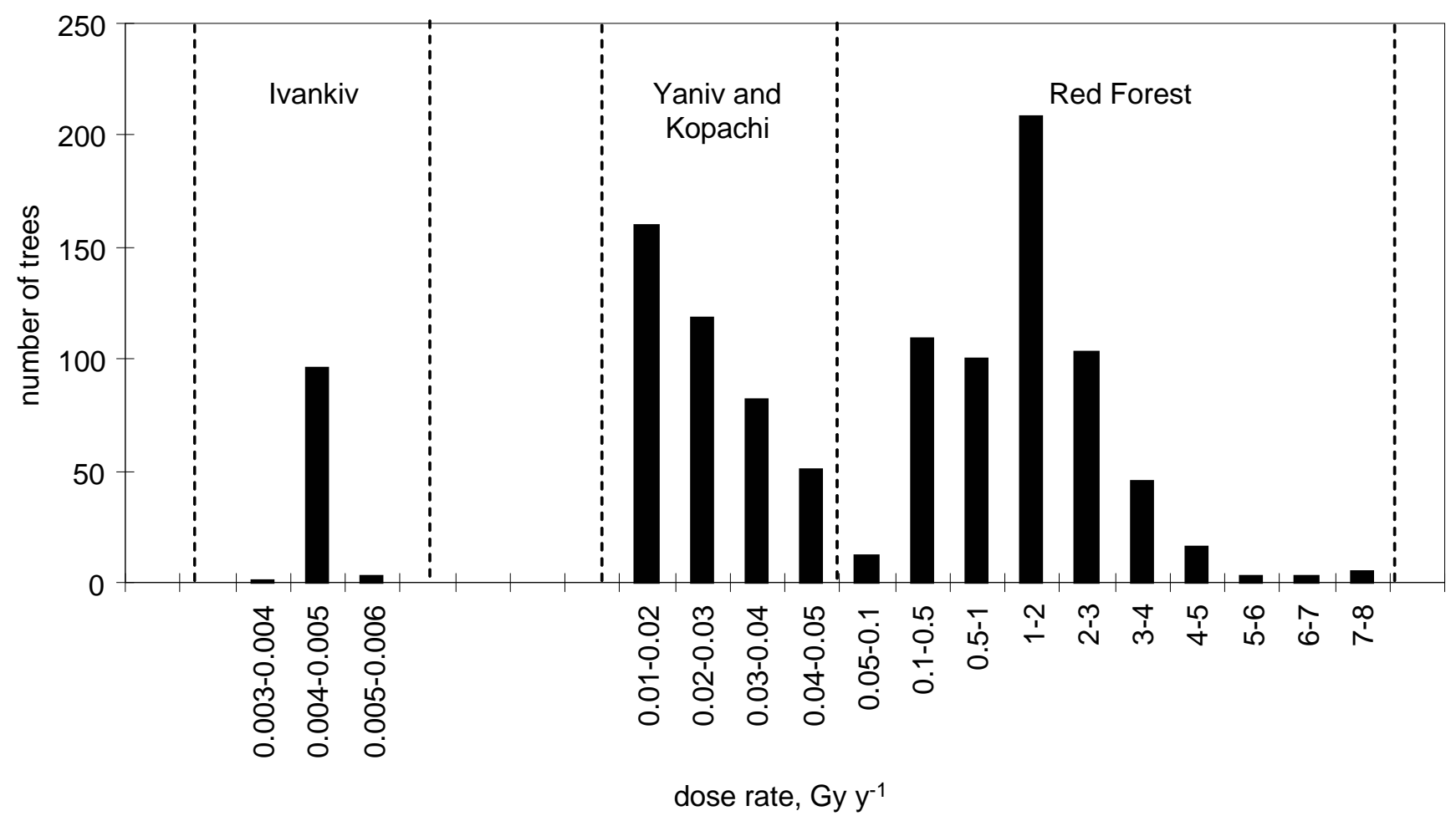

Fig. 2. Dose rate distribution in the sampled trees. The dotted lines show the boundaries of the three clusters of sites included in the sampling plan - the Ivankiv (control), KopachiYaniv, and Red Forest sites. 


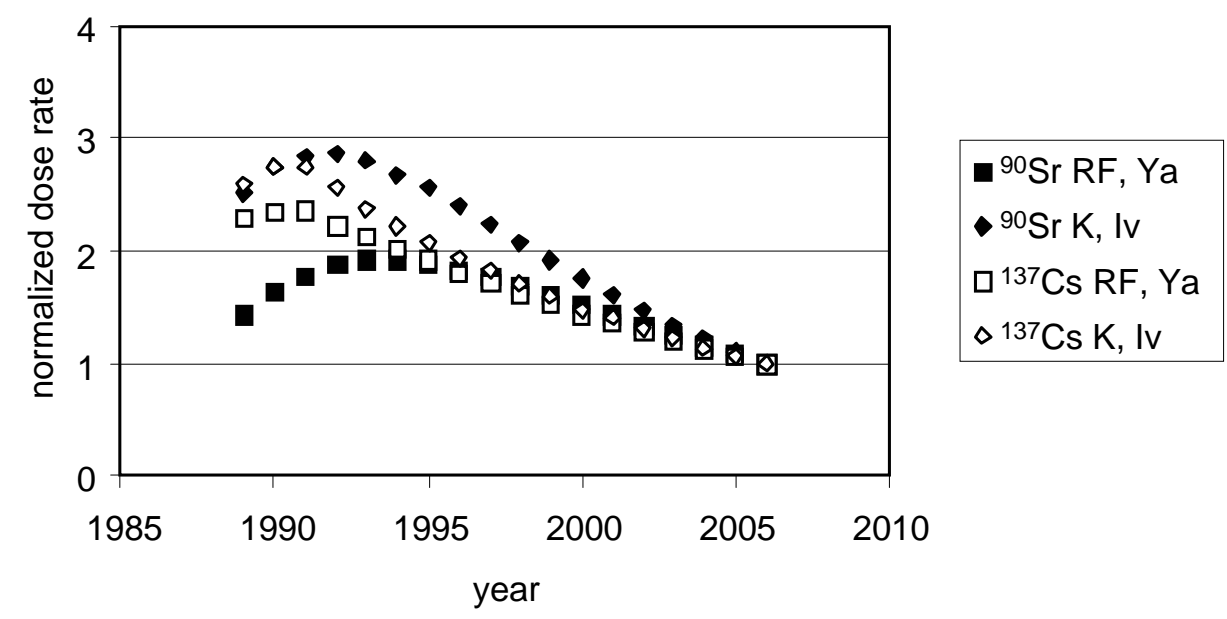

a

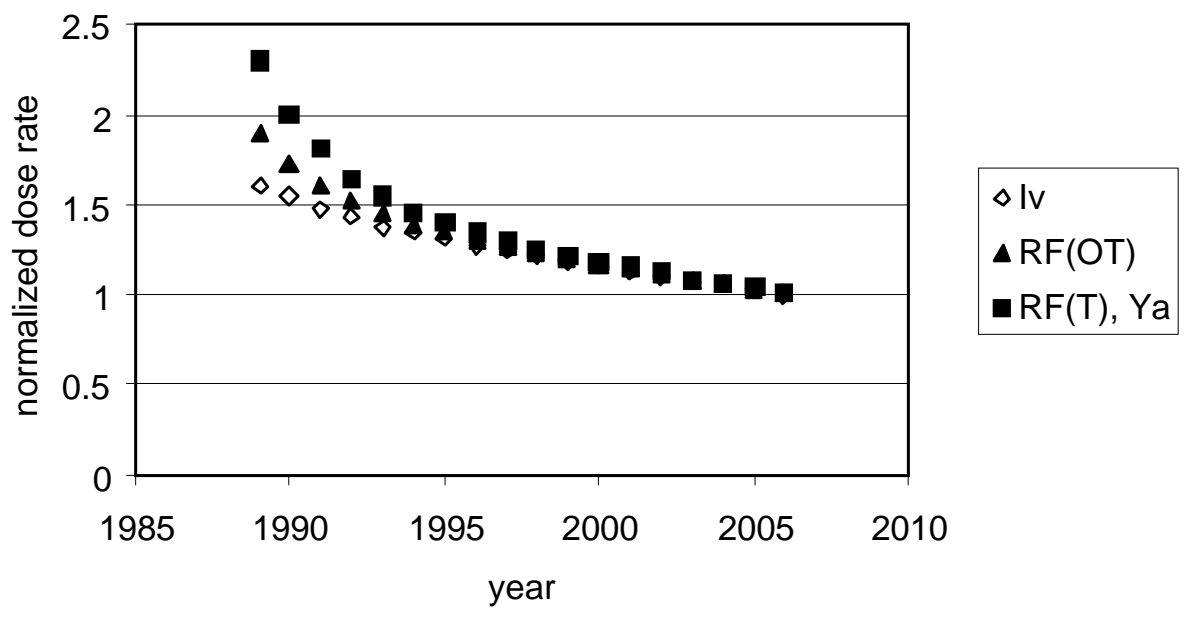

b

Fig. 3. Dynamics of the normalized dose rate (unitless) from incorporated radionuclides (a) and from external sources (b) for trees from the Red Forest (RF), Kopachi (K), Yaniv (Ya), and Ivankiv (Iv) sites. The dynamics for the trees growing on the trench (T) and outside the trench (OT) are shown for the Red Forest site. 


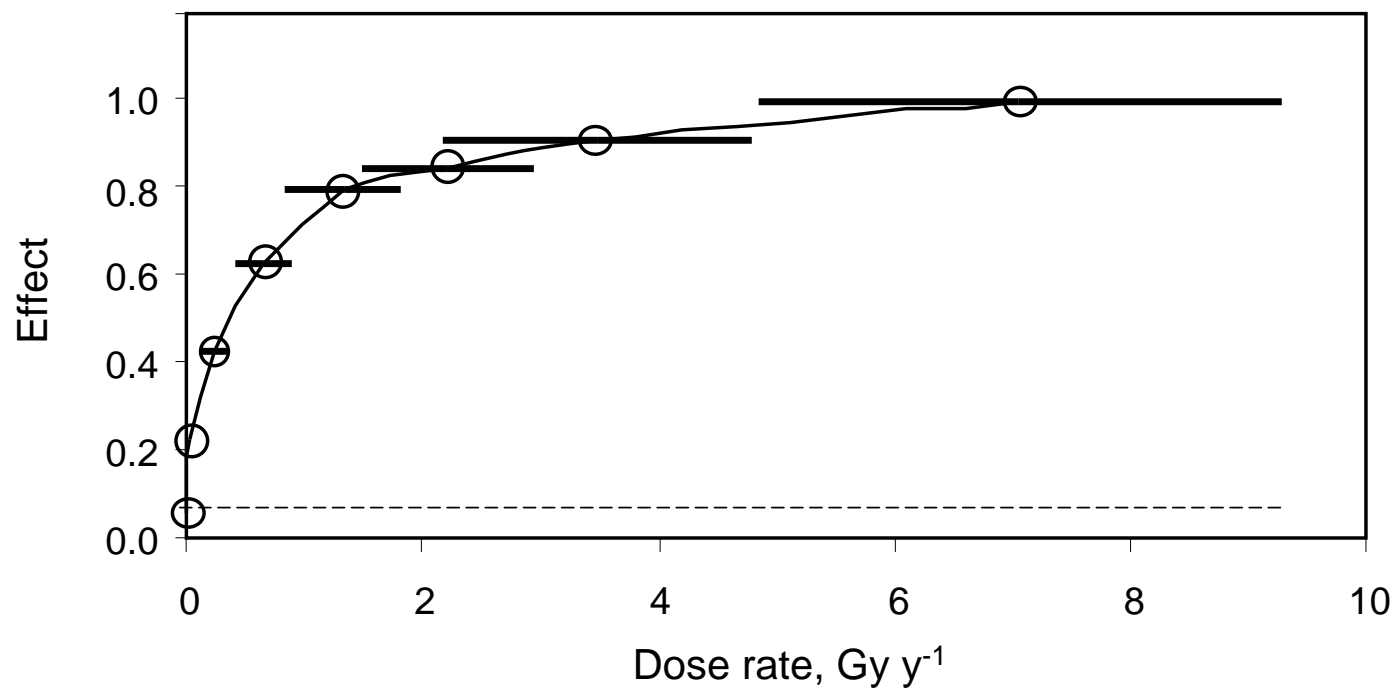

Fig. 4. Effect (probability of morphological changes) as a function of dose rate in Scots pine trees. The dotted line shows the background (control site) value of frequency. The circles indicate the average dose rates for the tree groups, and the horizontal bold lines correspond to the ranges of the combined standard deviations for each group. 


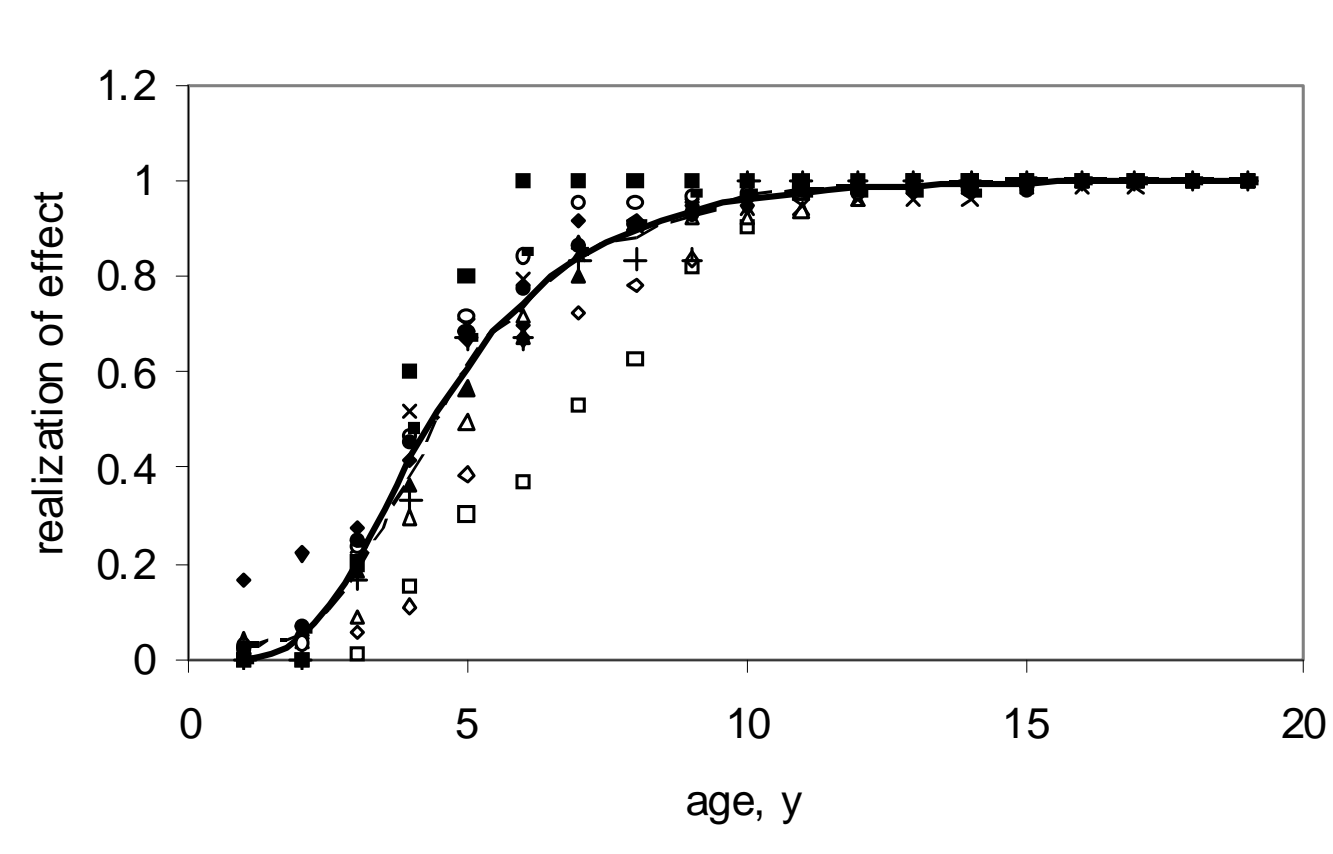

\begin{tabular}{|cl|}
\hline+ & 0.0111 \\
$\square$ & 0.0379 \\
$\circ$ & 0.068 \\
. & 0.36 \\
$\Delta$ & 1.12 \\
$\triangle$ & 1.9 \\
$\times$ & 2.7 \\
$\circ$ & 3.8 \\
. & 5.1 \\
- & 6.6 \\
- & 12.1 \\
--- & - average \\
\hline
\end{tabular}

Fig. 5. Dynamics of formation of morphological changes in trees from various dose groups (the average dose rates for each group are given in the legend for 1990, Gy $\mathrm{y}^{-1}$ ). 


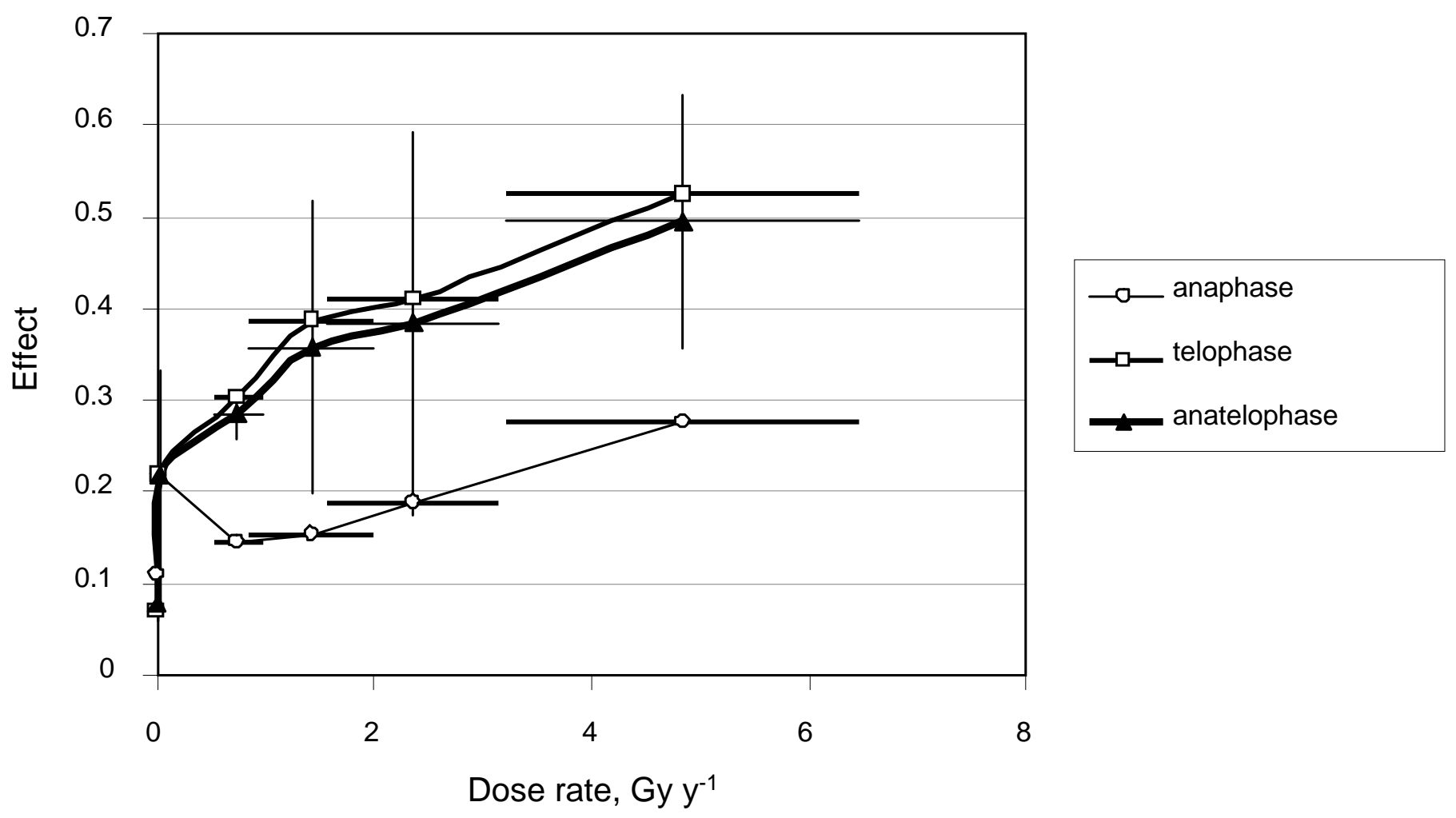

Fig. 6. Effect (probability of cytogenetic changes) as a function of dose rate in seed germs of Scots pine trees. The horizontal lines represent a range of the combined standard deviations for the dose rate of the upper meristem of the given group. An uncertainty of the effect (a standard deviation of the values for a set of trees in each group) is shown by vertical lines only for the anatelophase. 


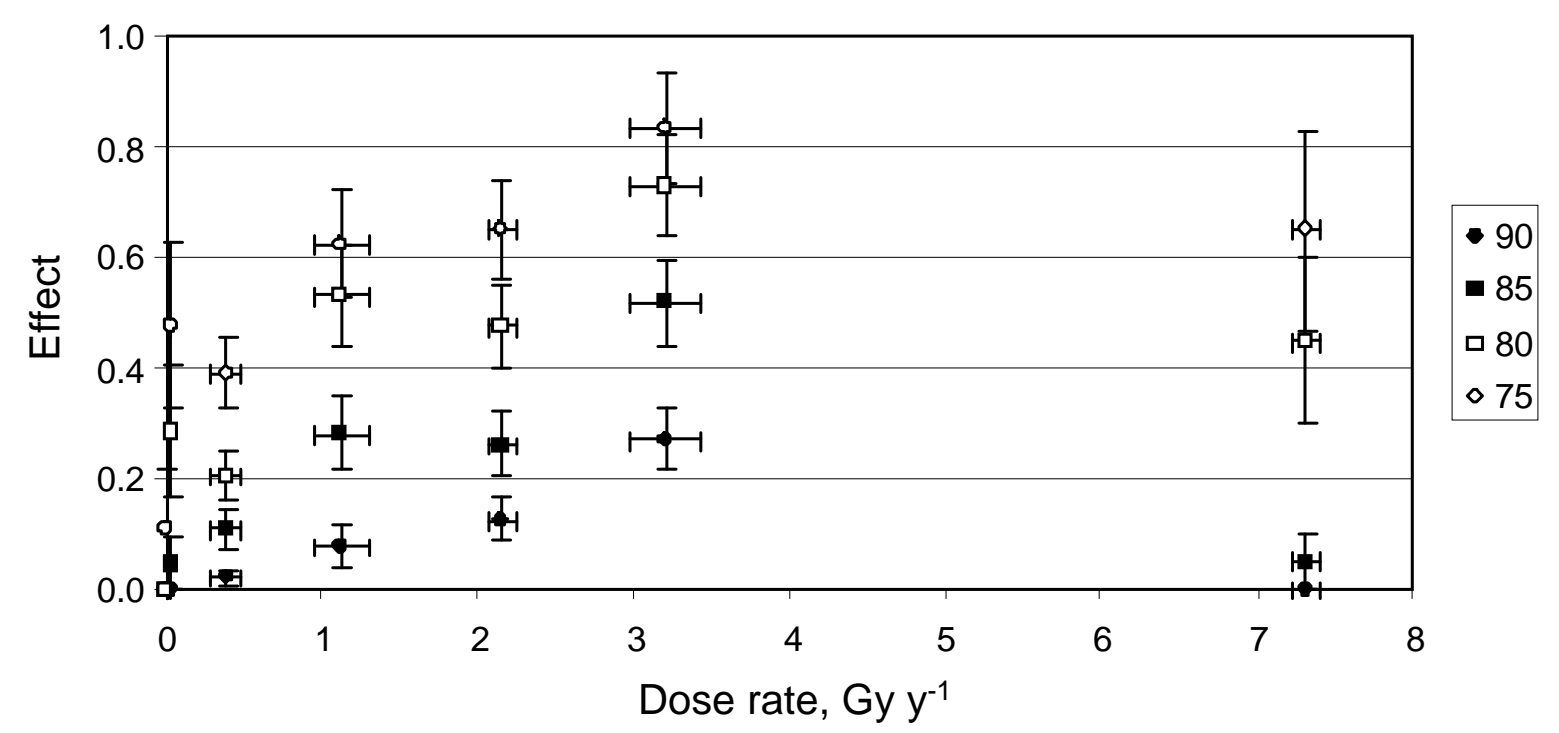

a

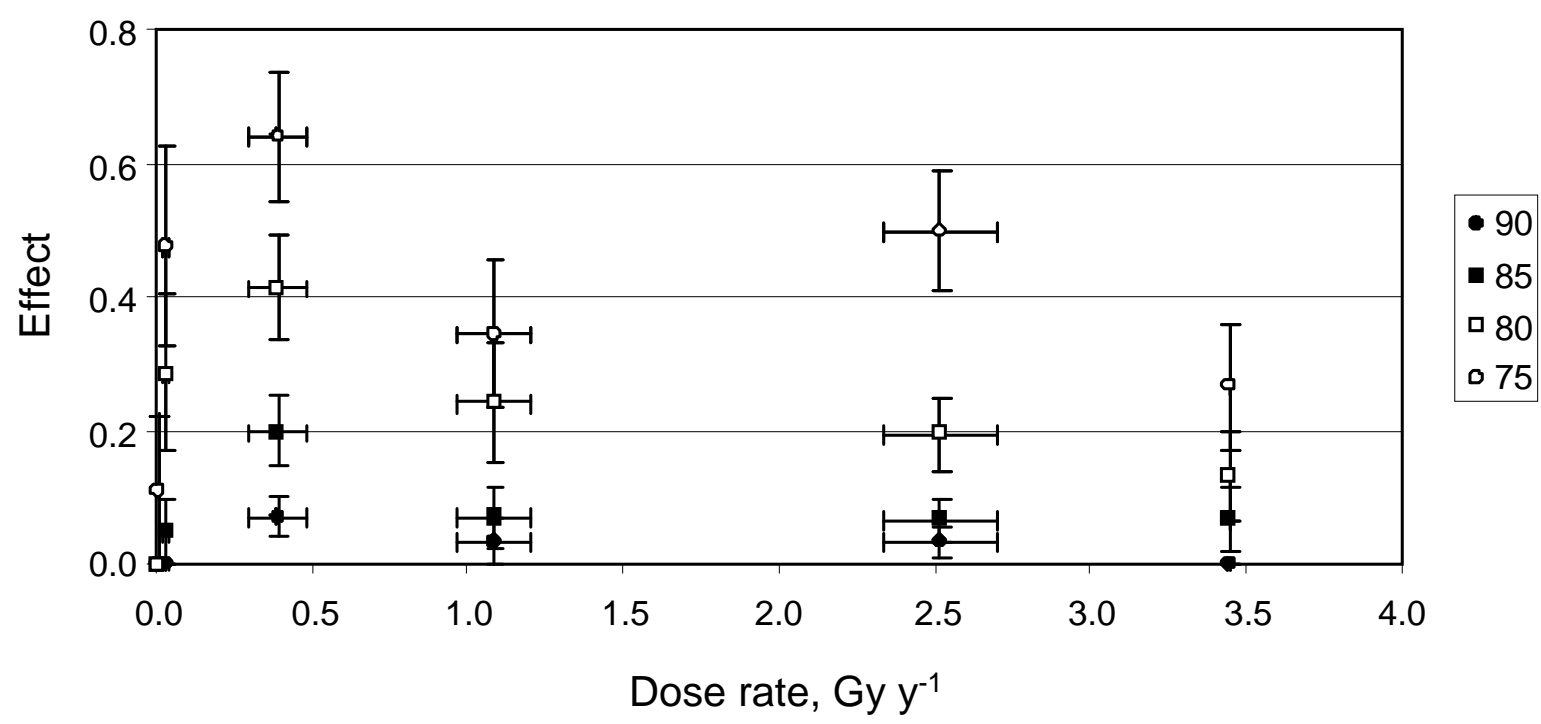

$b$

Fig. 7. Effect (probability of cytogenetic changes) as a function of dose rate in the cells of the upper meristem for various $v$ values (\%, given in the legend) for trees with (a) and without (b) morphological changes. 


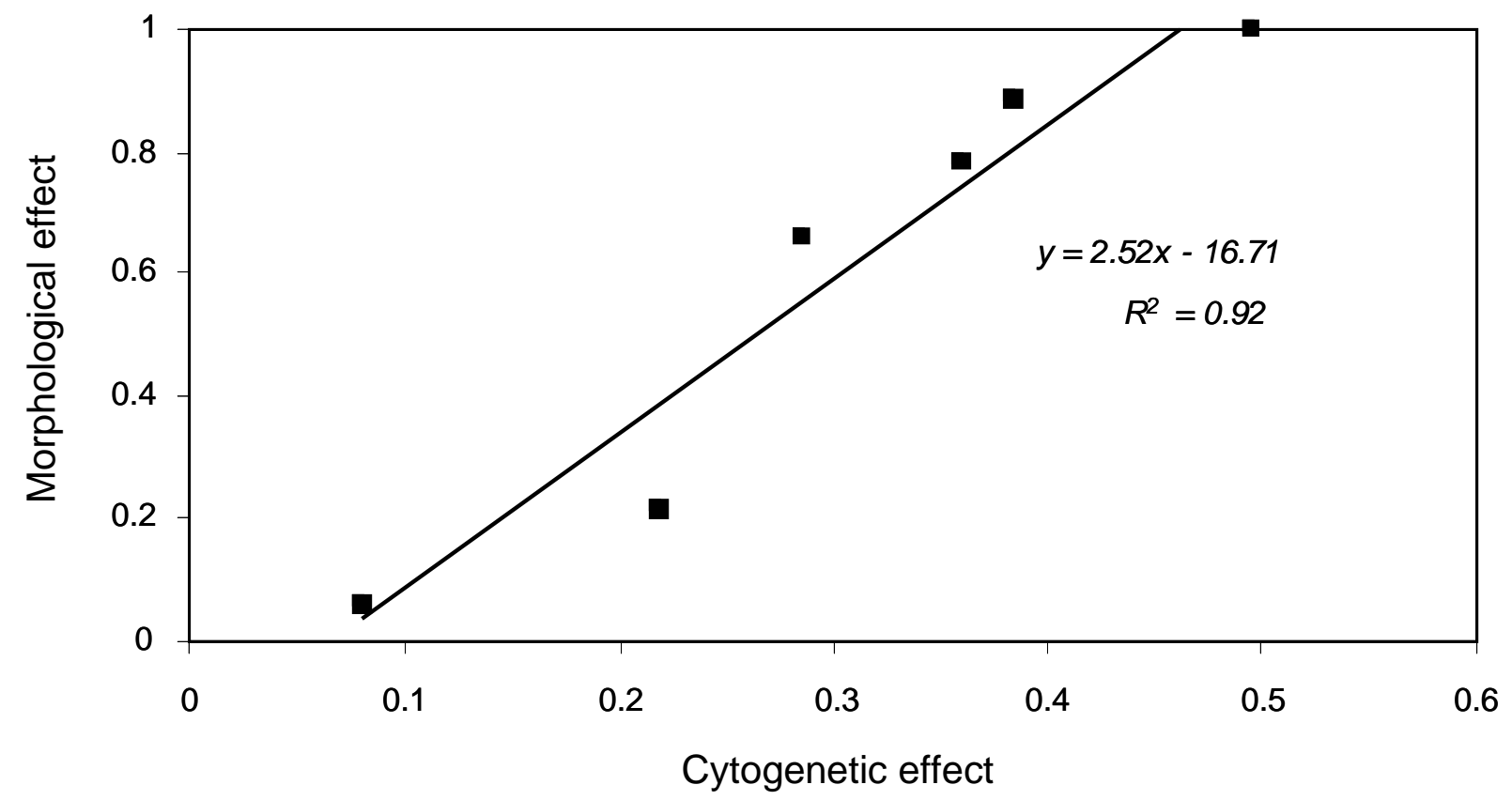

Fig. 8. Correlation between cytogenetic effect in germs and morphological effect for Scots pine trees. 


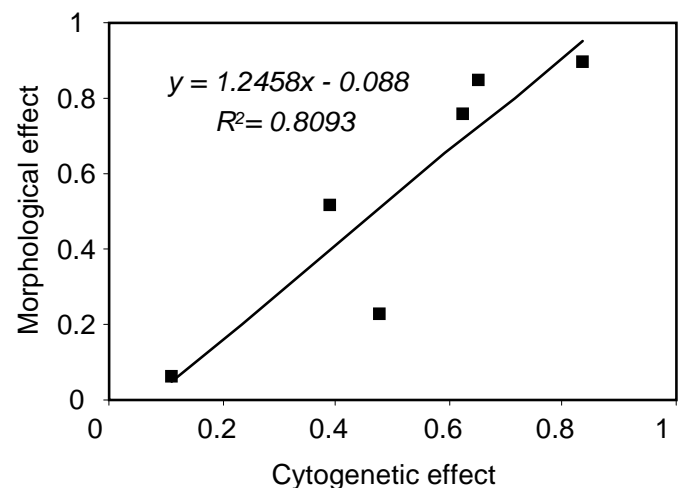

a

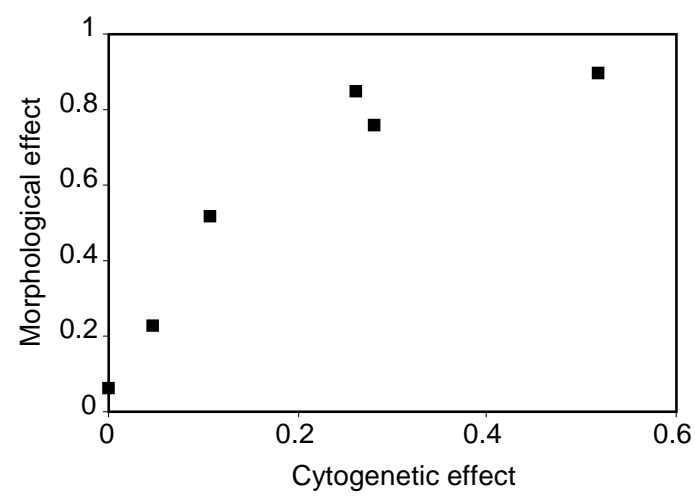

C

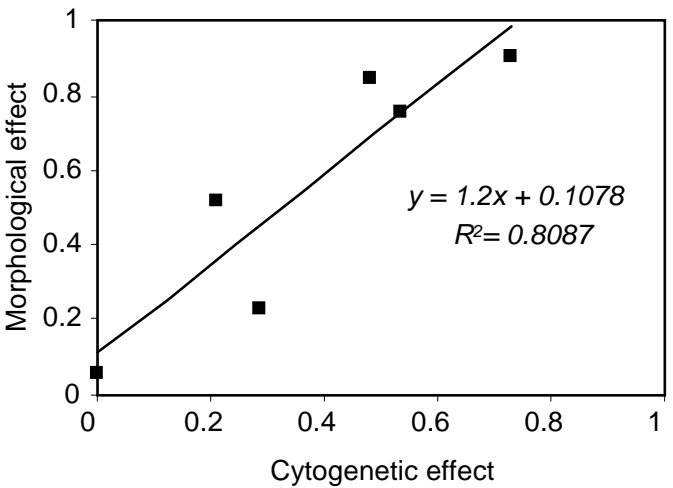

b

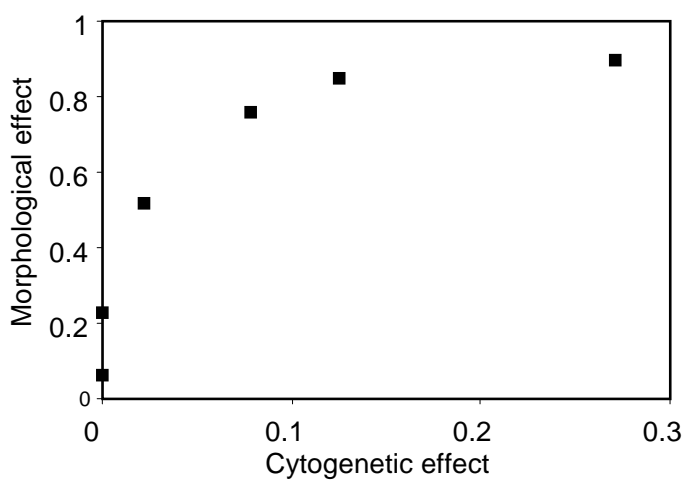

d

Fig. 9. Correlation between cytogenetic effect in cells of the upper meristem and morphological effect at $v$ values of $75 \%$ (a), $80 \%$ (b), $85 \%$ (c), and $90 \%$ (d). 
Table 1. Time-dependent concentration ratios $\left(a_{i, j}\right)$ for ${ }^{90} \mathrm{Sr}$ in the pine tree organs.

\begin{tabular}{ccccccccc}
\hline Month (j) & \multicolumn{7}{c}{ Organ (i) } \\
\cline { 2 - 8 } & $\begin{array}{c}\text { Needles, } \\
\text { 1 year old }\end{array}$ & $\begin{array}{c}\text { Needles } \\
>\mathbf{1 y}\end{array}$ & $\begin{array}{c}\text { Offshoot } \\
\text { branches }\end{array}$ & Branches & $\begin{array}{c}\text { Outer } \\
\text { bark }\end{array}$ & $\begin{array}{c}\text { Inner } \\
\text { bark }\end{array}$ & Stemwood & Buds \\
\hline Jan & 1.2 & 4.0 & 1.5 & 1.9 & 3.4 & 3.5 & 1.1 & 0.8 \\
Feb & 1.2 & 4.0 & 1.5 & 1.9 & 3.4 & 3.5 & 1.0 & 0.8 \\
March & 1.4 & 7.3 & 2.0 & 2.8 & 4.8 & 6.4 & 1.0 & 1.2 \\
April & 1.9 & 7.3 & 3.4 & 2.3 & 4.5 & 6.0 & 1.2 & 2.2 \\
May & 1.0 & 3.6 & 2.5 & 1.9 & 3.9 & 4.7 & 1.0 & 1.4 \\
June & 0.5 & 1.7 & 1.6 & 1.8 & 3.6 & 3.9 & 0.8 & 1.0 \\
July & 0.9 & 2.6 & 1.5 & 1.8 & 3.7 & 4.1 & 0.7 & 1.5 \\
Aug & 1.5 & 4.1 & 1.8 & 1.8 & 4.0 & 5.0 & 0.9 & 1.8 \\
Sep & 1.2 & 3.9 & 1.6 & 1.9 & 3.9 & 5.8 & 1.2 & 0.8 \\
Oct & 1.2 & 4.0 & 1.5 & 2.0 & 3.4 & 5.3 & 1.5 & 0.8 \\
Nov & 1.2 & 4.4 & 1.5 & 1.9 & 3.4 & 3.5 & 1.2 & 0.8 \\
Dec & 1.2 & 4.0 & 1.5 & 1.9 & 3.4 & 3.5 & 1.1 \\
\hline
\end{tabular}


Table 2. Time-dependent concentration ratios $\left(a_{i, j}\right)$ for ${ }^{137} \mathrm{Cs}$ in the pine tree organs.

\begin{tabular}{ccccccccc}
\hline Month (j) & \multicolumn{7}{c}{ Organ (i) } \\
\cline { 2 - 9 } & $\begin{array}{c}\text { Needles, } \\
\text { 1 year old }\end{array}$ & $\begin{array}{c}\text { Needles } \\
>\mathbf{1 y}\end{array}$ & $\begin{array}{c}\text { Offshoot } \\
\text { branches }\end{array}$ & Branches & $\begin{array}{c}\text { Outer } \\
\text { bark }\end{array}$ & $\begin{array}{c}\text { Inner } \\
\text { bark }\end{array}$ & Stemwood & Buds \\
\hline Jan & 5.3 & 3.4 & 6.9 & 4.5 & 12.0 & 7.0 & 0.8 & 5.0 \\
Feb & 5.3 & 3.4 & 6.9 & 4.5 & 12.0 & 7.0 & 1.0 & 5.0 \\
March & 11.0 & 9.2 & 12.0 & 19.0 & 18.0 & 20.0 & 11.0 & 27.0 \\
April & 9.6 & 11.0 & 11.0 & 7.0 & 5.0 & 8.0 & 3.2 & 28.0 \\
May & 13.0 & 3.6 & 14.0 & 2.3 & 19.0 & 5.0 & 0.7 & 19.0 \\
June & 17.0 & 4.0 & 16.0 & 3.1 & 17.0 & 8.0 & 1.7 & 16.0 \\
July & 19.0 & 6.6 & 17.0 & 5.6 & 8.0 & 14.0 & 2.9 & 26.0 \\
Aug & 17.0 & 8.1 & 13.0 & 7.2 & 9.0 & 17.0 & 3.1 & 47.0 \\
Sep & 11.0 & 7.1 & 7.7 & 6.9 & 11.0 & 13.0 & 1.8 & 65.0 \\
Oct & 6.1 & 4.5 & 3.8 & 5.3 & 5.0 & 5.0 & 1.0 & 55.0 \\
Nov & 5.3 & 3.4 & 6.9 & 4.5 & 12.0 & 7.0 & 0.8 & 5.0 \\
Dec & 5.3 & 3.4 & 6.9 & 4.5 & 12.0 & 7.0 & 0.8 & 5.0 \\
\hline
\end{tabular}


Table 3. Cytogenetic defects detected in seed germs in Scot pine trees.

\begin{tabular}{ccccc}
\hline Dose rate, & Mitotic & \multicolumn{3}{c}{ Quantity of identified defects } \\
\cline { 3 - 5 } Gy y & index & Fragments & Bridges & $\begin{array}{c}\text { Double } \\
\text { bridges }\end{array}$ \\
\hline 0.0045 & 55 & 24 & 4 & \\
0.013 & 75.32 & 28 & 7 & 5 \\
0.022 & 76.01 & 34 & 1 & \\
0.017 & 68.29 & 38 & 5 & 1 \\
5.08 & 59.22 & 156 & 1 & 1 \\
5.30 & 63.6 & 92 & 4 & 2 \\
2.14 & 59.6 & 70 & 4 & 1 \\
1.73 & 70 & 145 & & \\
4.14 & 67.3 & 78 & 4 & 1 \\
1.75 & 79.39 & 61 & 1 & 1 \\
2.58 & 60.45 & 69 & 3 & \\
1.14 & 69.64 & 118 & & 2 \\
0.72 & 64.75 & 128 & 2 & \\
0.77 & 64.58 & 107 & 1 & \\
1.06 & 68.36 & 96 & & \\
\hline
\end{tabular}

